HORIZON 5 (2) 2016 : I. Research : K. Gemenetzis : 142-174

ФЕНОМЕНОЛОГИЧЕСКИЕ ИССЛЕДОВАНИЯ • STUDIES IN PHENOMENOLOGY • STUDIEN ZUR PHÄNOMENOLOGIE • ÉTUDES PHÉNOMÉNOLOGIQUES

DOI : I0.I8199/2226-5260-2016-5-2-I42-174

\title{
TRAUM-ERKUNDUNGEN
}

\section{KONSTANTIN GEMENETZIS}

MD, Psychoanalyst.

President of the International Federation of Daseinsanalysis (2009-2012), 10676 Athens, Greece.

E-mail: kon.gemenetzis@gmail.com

\section{DREAM EXPLORATIONS}

This paper is an attempt to explore the dreams along various ways. A critical crossroad is the point where the dream manifests itself as a figure of the Other. Dream interpretations (Sigmund Freud, Medard Boss), violate the alterity of the dreamer - they relate the dream to the constitution of the awake. Dream interpretations are answers to the "Whys" and the "Hows" of a dream. They are explanations that just soothe the uneasiness caused by the uncanny dream world. Few quotes from Elias Canetti's notes emphasize on the singularity of a dream and its mysterious, i.e. inexplicable nature. A brief critical review of Medard Boss's conception of dreams allows to understand a dream as magnifying mirror of the existential features decisive for the shortcomings one faces in his everyday life. In psychoanalytic practice (and not only here) we cannot grasp a dream by going straight to the point. "Free associations" and "free floating attention" guide us to other, indirect and unforseen ways of approach. Remembering and forgetting dreams is an experience different from remembering and forgetting things. The question "What is a dream?" is a trap because it demands an answer like "The dream is ...". A dream is not something, it is not a "that". We attempt to speak about dreams following a phrase in Odyssey - "sie gingen vorbei an den Toren der Sonne, an der Gemeinde Träume, und kamen dann schnell an ihr Ziel, zur Asphodeloswiese”. Further goes a brief discussion of Beckett's play for television ("Nacht und Träume"). And finally a revision of the famous Dschuang Dsi's dream ("Butterfly Dream") on the basis of a painting by Katsushika Hokusai "The chinese philosopher Sōshi looking at butterflies”.

Key words: Dreams, Sigmund Freud, Elias Canetti, Medard Boss, butterfly dream, Samuel Beckett, Hokusai.

(C) KONSTANTIN GEMENETZIS, 2016 


\section{РАЗВЕДЫВАНИЕ СНОВИДЕНИЙ}

\section{КОНСТАНТИН ГЕМЕНЕТЗИС}

Доктор медицины, психоаналитик.

Президент Международной федерации дазайн-анализа (2009-2012), 10676 Афины, Греция.

E-mail: kon.gemenetzis@gmail.com

Статья представляет собой попытку исследования сновидения различными способами. Ключевым местом в этом процессе становится точка, где себя предъявляет фигура Другого. Интерпретации сновидения (Зигмунд Фрейд, Медард Босс) вторгаются в инаковость сновидца - они соотносят сон с устройством бодрствования. Интерпретации сновидений есть ответы на разные “Почему” и “Как” сновидения. Они становятся теми объяснениями, которые лишь смягчают беспокойство, вызванное непостижимым и странным миром сновидения. Несколько цитат из работ Элиаса Канетти подчеркивают уникальность сновидения и его таинственность, его необъяснимую природу. Короткий критический обзор концепции сновидений Медарда Босса позволяет понять сновидение как увеличительное зеркало, приближающее и заостряющее экзистенциальный характер повседневно обнаруживающих себя перед нами наших несовершенств. В психоаналитической практике (и не только в ней) мы не можем схватить сновидение прямым непосредственным образом. “Свободные ассоциации" и “свободно плавающее внимание” ведут нас к Другому непрямыми и непредсказуемыми путями. Воспоминание и забывание сновидения - это совсем иной опыт в отличие от воспоминания и забывания вещи. Вопрос “Что есть сновидение” - это ловушка, поскольку требует ответа вроде “Сновидение - это...”. Но сновидение не есть “чтото”. В своем размышлении мы пытаемся разведывать сновидение, руководствуясь словами из Одиссеи - "Мчались они мимо струй океанских, скалы левкадийской / Мимо ворот Гелиоса и мимо страны сновидений / Вскоре рой их достиг асфодельного луга, который /Душам призракам смертных уставших - обителью служит"1. В завершение мы проводим короткое обсуждение известного сна Чжуан-Цзы (“Сон о бабочке”), обращаясь при этом к рисунку Кацусика Хокусай “Китайский философ Соси, созерцающий бабочку”.

Ключевые слова: Сновидения, Зигмунд Фрейд, Элиас Канетти, Медард Босс, сон бабочки, Самюэль Беккет, Хокусай.

\section{DIE TRÄUME SIND OHNE “WARUM”}

Wie kommt Freud zu der Behauptung, die Träume können gedeutet, d.h. für ihn: erklärt werden? Freud stellt diese Frage nicht mehr. Vielleicht ist ihm die Antwort allzu selbstverständlich: Die Träume können erklärt werden, wenn eine noch vorgängigere Voraussetzung gilt, wenn sie nämlich überhaupt einen Grund haben. d.h. ein "Warum”. Das Warum verlangt eine Begründung. Wenn ein Traum

\footnotetext{
1 Восстановлено по: Гомер. Одиссея. Пер. с древнегреческого В. Вересаева (Прим. ред.).
} 
seinen Grund hat, so wird er als Folge dieses seines Grundes vorgestellt. Für die "Traumdeutung" ist also ein Traum nicht einfach Traum. Er ist auf seinen Grund im Rahmen einer Grund-Folge Beziehung angewiesen.

In der "Traumdeutung" wird die Verbindung eines Traumes mit seinem Grund. d.h. seine Begründung, durch die Deutung geleistet. Die Deutung "ersetzt" (Freud, 1998a, 100) einen Traum durch etwas anderes, so dass dieser Traum, der "an sich keine soziale Äusserung, kein Mittel der Verständigung” (Freud, 1933, 8) ist, nun als ein "sinnvolles psychisches Gebilde" (Freud, 1998a, 1) vorgestellt wird, das "in das psychische Treiben des Wachens einzureihen ist" (Freud, 1998a, 1).

Die freudsche Traumdeutung verbindet die Träume mit dem Wachen und so stellt sie die "Verkettung unserer seelischen Aktionen" (Freud, 1998a, 100) wieder her.

Dieser umfassende Begründungszusammenhang, wo jegliche "seelische Aktion" mit den anderen verbunden ist, z.B. die Träume mit dem Wachen, stellt eine Voreingenommenheit der "Traumdeutung” dar. Freud übernimmt sie ohne weiteres. Dass er darüber nicht spricht, heisst keineswegs, er kenne sie nicht. Im Gegenteil, die ganze "Traumdeutung" und die ganze freudsche Psychologie ist mit vollem Bewusstsein vom Anspruch der Warum-Frage, alles nach seiner Begründung und Erklärung abfragen zu können, voreingenommen. Der blosse Gedanke an einen Menschen, der schon bei einer "kleinen Zufälligkeit" (Freud, 1998c, 21) die Notwendigkeit ihrer Erklärung in Frage stellen würde, löst bei Freud ein Erbeben aus:

\footnotetext{
Was meint der Mann damit? Will er behaupten, dass es noch so kleine Geschehnisse gibt, die aus der Verkettung des Weltgeschehens herausfallen, die ebensogut nicht sein könnten, wie sie sind? Wenn jemand so den natürlichen Determinismus an einer einzigen Stelle durchbricht, hat er die ganze wissenschaftliche Weltanschauung über den Haufen geworfen. (Freud, 1998c, 21)
}

Freud hat Recht. Vielleicht die ganze "wissenschaftliche Weltanschauung", sicher aber die ganze freudsche und alle sonstige Psychologie steht und fällt mit der Frage, ob ein "noch so kleines Geschehnis", z.B. ein Traum, erklärt, d.h. ergründet und begründet und in das Beziehungsgeflecht eines "Systems" eingeordnet werde, oder - ob es keine Erklärung brauche. Freud ist sicher: "Unser Freund wird die Konsequenz aus seiner ersten Antwort nicht ziehen wollen, er wird einlenken [...]" (Freud, 1998c, 21).

Und wenn "unser Freund" nicht "einlenken" wird? Wenn, während Freud von der "Verkettung des Weltgeschehens" spricht, unserem Freund das Wort einfallen würde: "Die Ros ist ohn warum; sie blühet, weil sie blühet" (Angelus Silesius, 1949)? 
Ob eine "kleine Zufälligkeit", z.B. ein Traum oder eine Blume doch ausreicht, um die ganze "wissenschaftliche Weltanschauung" "über den Haufen" zu werfen?2 Alles kommt darauf an, ob ein Traum unter sein Warum gestellt zu werden braucht, ob nämlich dieser Traum erklärt und durch etwas anderes ersetzt werde und folglich, als solcher, über den Haufen geworfen werde, oder ob ein anderer Weg möglich sei: ein Traum, als der Traum, der von sich aus erscheint, ohne Warum.

Diese Möglichkeit, dass ein Traum uns als ein solcher, ohne Warum, ansprechen könnte, ist im abendländischen Denken nie beachtet worden. Schon Aristoteles fragt (Aristoteles, 1832, 64):

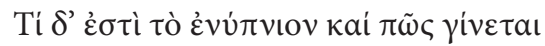

Was ist der Traum und wie entsteht er

Das "und" ist hier eher explikativ zu hören: Was ist der Traum und (das heisst:) wie entsteht er. Das Sein des Traumes wird hier zum ersten Male als Entstehung des Traumes ausgelegt ${ }^{3}$. Die Träume selbst, ohne Warum, bleiben vergessen. Dies auch und vor allem dort, wo anscheinend über die Träume selbst gesprochen wird. So Freud: "Der Traum ist an sich keine soziale Äusserung, kein Mittel der Verständigung" (Freud, 1998c). Er ist durch "Fremdartigkeit und Unkenntlichkeit" (Freud, 1998a) gekennzeichnet.

Fremd sind aber die Träume "an sich" nicht. Hier liegt ein weiterer entscheidender Fehler Freuds. Fremd sind die Träume erst für dasjenige Denken, das es darauf abgesehen hat, sie zu erklären, d.h. mit den "seelischen Aktionen des Wachens" in einen Zusammenhang zu bringen - wozu sich die Träume von sich aus überhaupt nicht bieten.

Die Ansicht, die Träume würden im Zusammenhang mit dem Wachen stehen, kann durch die Darstellung einer Traumdeutungstechnik nicht als "richtig" "bewiesen" werden. Es ist umgekehrt die Herrschaft des Warum im abendländischen Denken, welche die Verbindung der Träume mit dem Wachen verlangt. Dieser Anspruch wird nun in der "Traumdeutung" geltend gemacht. Freud meint, von den Träumen "an sich" zu sprechen, er spricht aber von den Träumen nur hinsichtlich

2 Die Frage des wissenschaftlichen Denkens, seiner Tradition und seiner Möglichkeiten, ist eine Frage, die das Werk Martin Heideggers durchzieht und bestimmt. Die hier unternommene Kritik der "Traumdeutung" bewegt sich im Rahmen der umfassenden, von Heidegger entfalteten Frage nach dem Sinn des wissenschaftlichen Denkens.

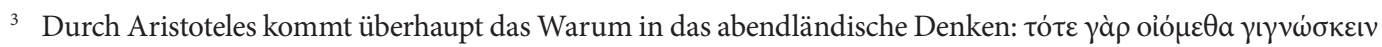

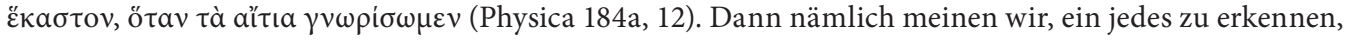
wenn wir die Gründe erkannt haben. 
ihres in diesen selbst nicht auszumachenden Grundes. Es ist erst für das aufs Warum eingestellte Auge, dass die Träume selbst unverständlich, fremd und unkenntlich sind. Dieses Auge ist für die Träume selbst blind.

Die Blindheit für die Träume selbst meint, dass keine noch so "selbstverständliche" Beziehung zwischen Wachen und Träumen je einen Grund für die Träume als Träume liefern könnte, d.h. dafür, dass es Träume gibt. Das Dass der Träume lässt sich nicht erklären, es ist keine Gegebenheit, wie auch das Dass des Wachens keine Gegebenheit ist. "Erklären" lassen sich allenfalls Traumgegebenheiten, die in einen Zusammenhang mit Gegebenheiten des Wachens eingezwängt werden könnten - wenn von diesen und nicht vom Dass der Träume ausgegangen wird. Dieses aber ist ein Erstes und Letztes, unerklärbar und unerklärlich, ohne Warum was von Freuds "Fremdartigkeit und Unkenntlichkeit" der Träume weit entfernt ist.

Träume ertrage ich nur unberührt und ganz, als Geheimnis. Sie sind so fremd, dass man sie sehr langsam begreift. [...] Wehe dem Narren, der sie gleich deutet, er verliert sie und fasst sie nie wieder, sie welken, bevor sie ihm grün waren. (Canetti, 1972, 255)

Warum ist derjenige, der Träume deutet, ein Narr? Warum verliert er sie und sie nie wieder fasst? Canetti fährt weiter:

Das Einzigartige jedes Traums wird von den Wenigsten geahnt, wie könnten sie ihn sonst zu irgendeinem Gemeinplatz entblössen. (Canetti, 1972, 255)

Die psychologische Deutung eines Phänomens ebnet sein Einzigartiges ein. Genauso wie der Apfel, der auf den Kopf Newtons fällt, seine Einzigartigkeit verliert, wenn dieser eine Fall unter der Alleinherrschaft des Gravitationsgesetzes sich unterordnet. Jener Apfel, der damals auf jenen Kopf gefallen ist, jener Traum, den ich in jener Nacht geträumt habe, wenn sie zu Objekten der Wissenschaft werden, der Physik, der Psychologie, verenden zu "Gemeinplätzen". Canetti nochmals:

Unsere moderne Traumdeutung macht den Menschen nur gewöhnlicher. Sie verfärbt das Bild ihrer inneren Spannung, statt es zu erleuchten (Canetti, 1972, 221).

\section{WACHHAFTES TRAUMLEBEN}

Medard Boss hat ebenfalls kein Gespür für das "Geheimnis", das "Fremdartige" der Träume. (Dies vor allem in seinen einschlägigen Texten. In seinen unbewachten Stunden, wo er frei vom Zwang der Polemik und der Selbstbehauptung war, war er anders.) Er achtet nicht auf die so oft wiederholten Sätze Heideggers über die Ferne 
des Nahen, wo die Nachbarlichen "auf getrenntesten Bergen" (Heidegger, 1983, 85) wohnen $^{4}$ - z.B. Wachen und Traum.

In der Indienfahrt eines Psychiaters, also schon noch vor seinem ersten Traumbuch, zitiert Boss einen indischen Weisen:

Kein Mensch träumt von einer schwerfälligen, eingepanzerten Schildkröte, dem es nicht schildkrötenhaft eng und beschwerlich zumute ist. (Boss, 1976, 221)

Hier ist der Traum auf die Stimmung des wachen Menschen zugeschnitten. Sein "schildkrötenhaft enges und beschwerliches" Wachleben bestimmt eben seinen Traum. In dieser Hinsicht segelt Boss im Kielwasser der freudschen Traumauffassung. Das Duett Wachen-Schlaf wird einzig auf den Menschen, und überdies auf den wachen Menschen hin ausgelegt. Der indische Weise und Medard Boss hätten nie mit Dscuang Dschi gesagt:

Nun weiß ich nicht, ob dieser Mensch geträumt hat, dass er eine Schildkröte sei, oder ob die Schildkröte geträumt hat, dass sie dieser Mensch sei [...]. (Boss, 1976, 221)

\section{AUF DEN TRAUM ZU. VOM TRAUM WEG}

In Ratschläge für den Arzt bei der psychoanalytischen Behandlung schreibt Freud: “Traumtexte, an denen mir gelegen ist, lasse ich von den Patienten nach der Erzählung des Traumes fixieren” (Freud, 1982, 173).

Medard Boss soll seine Kinder aufgefordert haben, ihre Träume am nächsten Morgen niederzuschreiben. Stolz verwies er auf seine Traumsammlung, die, wenn ich mich richtig erinnere, etwa 25.000 Traumerzählungen beinhaltete.

Weiss man über die Träume Bescheid, wenn man eine unzählige Menge davon zur Kenntnis nimmt? Ist es nicht so wie man behauptete, er würde mehr über den Tod wissen, wenn man viele Leichen gesehen hat? Kann ein Traum mittels eines Frontalangriffs seine Geheimnisse verraten?

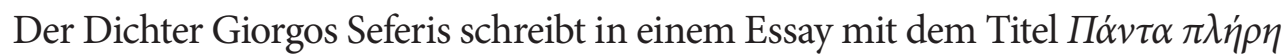
$\theta \varepsilon \omega \dot{v}$ (Alles voll von Göttern - nach Thales):

Was nun die Tempel betrifft, wenn ein sehr naher Freund versuchte, mit Hilfe von alten Texten ihnen näher zu kommen, so würde ich ihm raten, sich mit Texten vertraut zu machen, die ihn zu diesen auf Umwege führen, nicht durch direkte Beschreibungen. [...] Er möge sich diese Weiträumigkeit vorziehen. Und wenn dieser sehr nahe Freund von mir insistierte, ich solle konkreter werden, so würde ich ihm sagen, dass in diesen

4 Vgl. Heidegger $(1986,107)$ und Heidegger $(1976,107)$. 
Tagen, wo ich die vorliegenden Zeilen niederschrieb, Homers Verse über die fünfzig Mägde im Palast Alkinoos im Sinn hatte [...] - dermassen entfernt war ich. (Seferis, 1974)

Und warum sollen wir, um einer Sache näher zu kommen, in einem Solchen Sinne entfernt sein? Der Musikhistoriker Thrasyvoulos Georgiades schreibt im Vorwort von "Nennen und Erklingen":

Die Andersartigkeit meines Vorgehens lässt sich schon daran erkennen, dass die Darstellung eine bevorzugte Verwendung von Analogien (Metaphern, Bildern) aufweist. Eine Analogie ist aber kein Beweis; sie kann nur auf das Nicht-Beweisbare, wohl aber Einleuchtende eines Sachverhalts, eines Phänomens, eines Faktums hinweisen; sie kann lediglich helfen, das Phänomen einzusehen. (Georgiades, $1985,18)$

Wird nicht die Weiträumigkeit, von der Seferis spricht, in der Analyse gerade durch die analytische Grundregel eröffnet, die einen frei lässt, alles zu sagen, was ihm einfällt, ohne auf etwas Besonderes, z.B. einen Traum, Rücksicht zu nehmen? Auf ihn zu fixieren? Welche Fixierung ebenfalls der "freischwebenden Aufmerksamkeit" des Analytikers Gewalt antun würde?

Ich sage es mal aphoristisch: Die wesentlichen Dinge, und unser Beruf hat mit wesentlichen Dingen zu tun, sind unfassbar, unerklärbar, unbeweisbar. Sie liegen nicht im Hoheitsgebiet der Erkenntnis. Sie erscheinen, und zwar wenn sie sich in einem anderen Licht zeigen. Es ist, und hier denke ich an die Zeit, wo ich Unterassistent im Anatomielabor war, wie Im Mikroskop, wo, wenn einem Gewebe eine färbende Substanz beigegeben wird, erst dann Zellen zum Vorschein kommen, die vorher unsichtbar waren. Und, in unserem Fall, schon ein solches "asymmetrisches" Erscheinen ist an sich heilsam. Analytische "Grundregel" und "freischwebende Aufmerksamkeit" sind gerade Voraussetzungen für die mögliche Ankunft dieses anderen Lichtes.

\section{TRAUMERINNERUNG UND TRAUMVERGESSENHEIT}

Schon das Wort "Er-innerung" ist irreführend. Es kommt keine Verlegung in ein Inneres vor. In der Vergegenwärtigung werde ich vielmehr in einer immer anderen Weise an die Zeit und an den Ort des vergegenwärtigten nicht-mehrAnwesenden verlegt. Schon die Rede vom "Ich" ist hier problematisch. Denn in der Vergegenwärtigung des Vergangenen werde ich selbst einer Verlegung an jene Zeit und an jenen Ort unterzogen. 
Nun, wenn wir das Wort "Erinnerung” unter diesem Vorbehalt gebrauchen wollen: die Erinnerung an einen Traum unterscheidet sich von der Erinnerung an Momente des Wachens. Ein Traum stellt eine eigentümliche Erinnerung dar. Denn die der Erinnerung innewohnende Verlegung ist radikal. Man müsste eher von Verrückung sprechen - Verrückung in eine andere und jedes mal andere Welt. Man wird ent-setzt. Die geläufigen Traumdeutungen, aber schon die auf eine mögliche Deutung hin angelegten Traumerzählungen, wären dann eher Bollwerke gegen das Sich-Entsetzen in die Traumwelt.

Das Vergessen ist ebenfalls kein Akt. Zum Vergessen gehört, dass das Vergessen selbst vergessen bleibt. Die Lehre von der Verdrängung, z.B. der frühen Kindheit, ist Unsinn. In der frühen Kindheit war ich bloss ein Anderer. Jene Zeit bleibt heute unzugänglich, so wie z.B. ein Software, den ich in meinem alten Windows-Computer benutzte, auf dem Display meines neuen Apple-Computers einfach nicht da ist. Es ist spurlos verschwunden.

Hier zeichnet sich jedoch ein Unterschied zur Software-Inkompatibilität ab. Die frühe Kindheit und oft die Träume, und sonst Vergangenes, wenn auch vergessen, hinterlassen Spuren. Von diesen spricht Friedrich Hölderlin in Brot und Wein:

Ließ zum Zeichen, daß einst er da gewesen und wieder

Käme, der himmlische Chor einige Gaben zurück

Und Wittgenstein:

Aus der früheren Kultur wird ein Trümmerhaufen \& am Schluss ein Aschenhaufen werden; aber es werden Geister über der Asche schweben. (Wittgenstein 1994, 25)

"Zeichen" und "Geister" wären Namen für die Art und Weise, in der Vergangenes uns angeht.

We are such stuff as dreams are made of, and our little life is rounded with a sleep

- sagt Prospero in Schakespeares The Tempest. Unser "kleines Leben" be-wegt sich unter einem Himmel von Zeichen und Geistern. Dieser Himmel wäre der Ort der Träume - der erinnerten, als auch der vergessenen.

Heidegger schreibt, das Wesen der Sprache hat uns gerade in Augenblicken gestreift, wo uns ein Wort auf der Zunge liegt und zugleich ausbleibe. Vielleicht verhält es sich mit den Träumen ähnlich: Augenblicke, wo es mir einleuchtet, dass ich geträumt habe, die Traumgeschehnisse nicht abrufbar sind, wohl aber das 
Traumgeschehen als solches - seine Duft sozusagen, seine Aura. In einem solchen Sinne umgeben die Zeichen genannt "Träume" unser "kleines Leben".

Das Dass des Träumens ist nicht mit seinem Was des Geträumthabens zusammenzubringen. Der Traum als solcher ist ein Anderes. Es liegt in seiner Natur, dass es flüchtig bleibt, uns in seinem Flug anrührt ohne jemals ergriffen und begriffen zu werden. Es zeichnet uns, indem es selbst in die Lethe zurüchzieht.

\section{TRÄUME}

Die Träume sind prophetish: es ist die Position des Traumbuches.

Die Träume sind Wunsherfüllungen: es ist die Position der Psychoanalyse.

Die Träume sind Produkte neurochemischer Prozesse: es ist die Position der Neurobiologie.

Die Träume sind ein therapeutisches Instrument: es ist die Position der meisten psychotherapeutischen Methoden.

Positionen. Leicht übernehmen wir sie. Selten merken es uns, dass eine Position nicht selbstständig ist, sondern auf eine Frage antwortet. Und noch seltener merken wir es uns, dass die Frage die Form der antwortenden Position schon bestimmt hat. Und noch seltener unterziehen wir die Frage selbst einer Prüfung. Die dargelegten Schritte zeigen den Weg an, den die vorliegende Erörterung gehen wird.

Die erwähnten Positionen sagen: "Die Träume sind dies und jenes ...". Sie antworten auf die Frage: "Was sind die Träume?"

Was sind die Träume? Diesmal werden wir die Frage und ihren Anspruch auf eine Antwort nicht befriedigen. Wir werden nicht auf sie hören. Wir werden sie hören.

Was sind die Träume? Die hörige Antwort wird die unausgesprochene Weisung der Frage, die Träume als ein Etwas vorzustellen, akzeptieren und vollstrecken. Sie wird die Träume übernehmen, überbringen und unterbringen in das jeweils angenommene "Was":

- in das Prophetische, das das Unscheinbare des Kommenden, die Grenze des "noch nicht" übertritt

- in den Wunsch, sei es auch der unmöglichste, der unbedingt erfüllt werden muss, wenn auch als Einbildung, in der angenommenen "Halluzination" des Traumes

- in den Anspruch der Wissenschaft auf Sicherheit, um derer Willen Träume auf ihr Messbares und Berechenbares reduziert werden, ein jämmerlicher Rest ihrer einstigen Fülle. 
- in die Selbstsucht eines "therapeutischen Prozesses", der sie zum Fundus fürs Wachen bestimmt und aus ihnen das herausnimmt, was er selbst ihnen zugesprochen hat.

Schon durch die - nun können wir es aussprechen - fatale Frage "Was sind die Träume?" liegt weitoffen der Weg zur Überschreitung ihres Masses, zum Begehen einer Hybris, die sie auf dem Prokrustesbett der Vorstellungen einer zügellosen Selbstherrligkeit vergewaltigt.

Was liegt an den Träumen, dass sie derart anfällig auf die menschliche Hybris, dieser ausgesetzt sind?

Vielleicht liegt es daran, dass die Träume die Sprache der Zeichen sprechen: weder sagen sie noch verbergen sie (Heraklit). Sie dulden nicht die uneingeschränkte Erschliessung, auf welche das Traumbuch und die Psychoanalyse aus ist, sie dulden nicht die uneingeschränkte Verhüllung und Verstummung, zu der sie die Neurobiologie und die Verhaltenswissenschaft verurteilen.

Die Träume sprechen die Sprache der Zeichen. Weder sagen sie noch verbergen sie.

A, die du geträumt, ist diejenige, die du im Wachen kennst, und sie ist es wiederum nicht. Und wenn du genug Ethos und Herz hast, um die A des Traumes zu achten, so hast du sie die Welt auf ihre Art bewohnen zu lassen. Du bist weder erlaubt, sie mit der A des Wachens zu identifizieren, noch sie zu einer Halluzination zu erklären.

Was sagt, jedoch sagend verbirgt, was verbirgt, jedoch verbergend sagt, hat die Eigenschaft des Zeichens - jenes, das nie "etwas" bezeichnet, sich selbst nie verleugnet.

Die Träume, als Zeichen, zeigen - im intransitiv. Ihre Anfälligkeit liegt in ihrer Natur selbst: Jedes Sagen über die Träume wird ihr Mass verletzen, entweder indem es zu viel sagt oder indem es zuviel verbirgt.

Es tut Not, und dies kann auch der Weg einer therapeutischen Begegnung sein, diese Verletzungen zu erfassen, auf sie hinzuweisen, sie zu verbieten in Verteidigung des Masses, d.h. Sorge tragend, dass die Träume Träume bleiben - und die Menschen Menschen bleiben, will sagen, dass sie, auch hier, bei den Träumen, zu sich finden.

\section{DIE GEMEINDETRÄUME}

Im April 2003 erhielt ich einen Artikel über den Traum. Ich versuchte, einen Antwortbrief zustandezubringen. Es wollte mir einfach nicht gelingen! Aus den 
Entwürfen blieb immerhin ein Satz bestehen: "Ich weiss immer weniger, was über den Traum zu sagen wäre und ich denke mit Entsetzen, dass ich in Wien einen Vortrag mit dem Titel 'Träume' halten muss". Eines Tages nun, samt Entsetzen und Nicht-wissen, machte ich mich tastend-schreibend auf den Weg der Träume.

Als Wegzeichen stand mir eine Stelle aus der Odyssee $(\Omega, 12)$. Dort wird die Fahrt der Seelen der von Odysseus getöteten Freier zum Hades geschildert. Die hier relevanten Verse lauten:

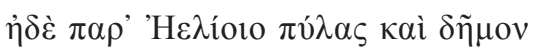
'Oveíp

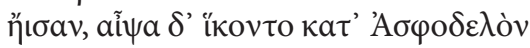
$\Lambda \varepsilon\llcorner\mu \tilde{\omega} v \alpha$ sie gingen vorbei an den Toren der Sonne, an der Gemeinde Träume, und kamen dann schnell an ihr Ziel, zur Asphodeloswiese

Die "Gemeinde Träume”... Sie liegt bei den "Toren der Sonne” und Hades der "Asphodeloswiese".

Die Stelle war mir ursprünglich aus Versen des neugriechischen Dichters Giorgos Seferis bekannt:

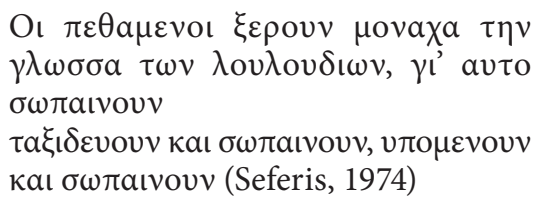

und nun folgen die homerischen Worte, die zweimal wiederholt werden:

\author{
Die Toten kennen nur die Sprache \\ der Blumen [der Asphodelen]; \\ deswegen schweigen sie \\ sie reisen und schweigen, sie \\ dulden und schweigen
}

PARA DĒMON ONEIRŌN, PARA DĒMON ONEIRŌN

Die Verse hab ich erstmals vor etwa vierzig Jahren gelesen. Keine Rede von den Träumen hat mich je so bewegt wie diese. Meine "Bewegung" ist jedoch bis heute stumm geblieben. Was ich Ihnen zu sagen habe, kommt aus einem Versuch, sie endlich sprechen zu lassen.

$\mathrm{Zu}$ Beginn erzähle ich einen kurzen Traum. Er stammt aus der Zeit meines Aufenthaltes im deutschsprachigen Raum, die mir anlässlich dieses Vortrages erneut präsent wurde: Ich bin mit Medard Boss (meinem damaligen Lehrer) an einem unbekannten Ort im Freien. Er schenkt mir einen Ring. An dem Abend, wo ich diese Zeilen zum ersten Mal aufs Papier brachte, hatte ich auch einen Brief an meinen Freund und Kollegen Hansjörg Reck geschrieben.

Eine Nacht war es, als ich den Boss-Traum hatte. Eine Nacht war es, als ich den Reck-Brief schrieb. Sind hier Nacht und Nacht gleich? Habe ich Ihnen gerade zwei nächtliche Ereignisse - Boss-Traum und Reck-Brief - erzählt? 
Die Nacht des Reck-Briefes war die Nacht vom 15ten Mai. Ich war in meiner Praxis in Athen; es war Vollmond; ich habe an meine Frau im 500 Kilometer entfernten Thessaloniki gedacht; ich sass an meinem Arbeitstisch bei einem Glas Schnaps; in den Nachrichten war das Neueste von der Pneumonie in China zu hören usw. Diese Nacht ist vom Reck-Brief nicht wegzudenken. Sie ist auch nicht von den sonst erwähnten Orten und Menschen wegzudenken, denn mit ihnen versammelte sich meine Lebenszeit zur Gegenwart jener Nacht.

Wie steht es nun mit der Nacht des Boss-Traumes? Sie, als die Nacht des BossTraumes, lässt sich nicht so wie die Nacht des Reck-Briefes beschreiben - der BossTraum kam mir ja erst beim Erwachen in den Sinn. Es hat keinen Zeitpunkt gegeben, wo ich zum Boss-Traum sagte, oder hätte sagen können: "Es träumt mir heute Nacht”. Hat das Verbum “Träumen” eine Gegenwartsform? - fragt Wittgenstein. Aber was nie gegenwärtig war, kann auch nie vergangen sein: Mein Traum ist nicht vergangen, so wie der Reck-Brief vergangen ist. Sofern das Verbum "Träumen" keine Gegenwartsform hat, hat es auch keine Vergangenheitsform: Der Satz "Ich habe geträumt..." kann nicht so gesagt werden wie der Satz "Ich habe einen Brief ... geschrieben".

Man könnte entgegnen, dass ich z.B. in einem Schlaflabor wohl wissen kann, wann einer träumt; ich kann ihn wecken; er kann es bestätigen und seinen Traum erzählen. Das Verbum “Träumen” hätte also doch eine Gegenwartsform! Dieser Einwand gibt mir die Gelegenheit, auf einen Unterschied hinzuweisen: Ein anderes ist es, zu wissen und ein anderes, zu sehen. Der Unterschied zwischen Sehen und Wissen ist in der Psychoherapie von äusserster Wichtigkeit. Er ist der Prüfstein, an dem entschieden wird, ob die Deutung, entsprechend ihrer Herkunft vom griechishen Wort DEIKNUMI ("zeigen”), ein Sehenlassen bedeutet, das einen ermuntert, die Augen aufumachen, oder ein Erklären, das zu nichtssagenden Verbindungen und Konstruktionen führt. Ich kann die Nacht des Boss-Traumes als die Nacht eines Traumgeschehens wohl erschliessen, aber nie sehen.

Die Nacht, die im Satz "Es träumte mir vergangene Nacht..." angesprochen wird, ist weder zur Gegenwart noch zur Vergangenheit meiner Lebenszeit je geworden. Nie hat sie mich in sich aufgenommen. Nie bin ich in ihr heimisch geworden. Ihr Unheimisches geht mich aber doch an - sie war ja die Nacht jenes Traumes. Diese Nacht ist un-heimlich.

Die gemeinte Unheimlichkeit kommt noch reiner zu Gesicht dort, wo es um die Nacht des traumlosen Schlafes geht. Der Unterschied des Satzes "Ich habe einen Brief geschrieben" vom Satz "Ich habe geschlafen" ist noch augenfälliger. Hier sticht 
das Fehlen der Gegenwarts- und der Vergangenheitsform des Verbums "Schlafen" in seiner geläufigen Verwendung schärfer ins Auge. Darauf kann ich mich aber heute nicht weiter einlassen.

Das Fremde der Träume und des Schlafes, das von den Behausungen der Menschen fernab Liegende, ihr Un-menschliches trifft das, was die Alten veranlasste, Träume und Schlaf als zum Göttlichen und zum Tode - zur "Asphodeloswiese" bezogen $\mathrm{zu}$ sehen. Es verbietet uns, den Traum sowohl im neuzeitlichen psychologischen Sinn vorzustellen, nämlich als etwas in einem phantastischen "Inneren" Ablaufendendes, als auch ins Anthropologische hineinzuzwängen, nämlich als vom Schlaf- und Wachzustand des Menschen Bestimmtes. Das Unheimliche ihrer Nächte lässt die Träume in einem anderen Licht erscheinen. Es zwingt die stutzenden Augen, sich daran zu gewöhnen.

Ich kann mir noch zwei Gruppen von Phänomenen denken, die diese seltsame Zeit-, besser: Weltlosigkeit - diese Unheimlichkeit - aufweisen.

Zum Einen sind es die alten Märchen. Oft beginnen sie mit dem Satz: Dar wöör maal eens... [“Es war einmal..."]. Dieses "einmal” ist von dem einen Mal, wo z.B. ich im Sommer des Jahres 1965 Wien besucht habe, radikal verschieden. Es verweist auf ein Uraltes, das genauso ausserhalb jeglichen Altertums und jeglicher Datierbarkei liegt wie die anscheinend greifbare "vergangene Nacht", in der ich dies und jenes träumte.

Zum Anderen denke ich an die vergangenen Dinge. Mit dem Wort “vergangen” meine ich jetzt gerade nicht z.B. eine kindliche Furcht, die im Erwachsenenalter immer wieder lebendig wird, oder einen Toten, der Einem über Jahre hinweg präsent bleibt, oder das, was Einem angetan wurde und ihn nicht in Ruhe lässt und nach Rache verlangt. Diese Dinge sind nur zum Schein vergangen. Das wortwörtlich Vergangene dagegen ist in die Fremde einer Ferne und Nähe gerückt, wo sein Datum nunmehr völlig irrelevant ist. So kann es mit all den gerade angeführten Beispielen geschehen. Der Weg dieser Verwandlung wird unter anderem in der therapeutischen Begegnung ausdrücklich eingeschlagen: Das Vergangene ist unterwegs zu seinem Vergangen-Sein. Am Ende dieses Weges nimmt das jetzt wortwörtlich Vergangene eben Traum- oder Märchengestalt an. Man könnte dieses Ende "Gedächtnis" nennen.

Als ich den Boss-Traum erzählte, habe ich eigens erwähnt, dass es ein Traum war. Hätte ich das Wort "Traum” ausgelassen und gesagt, Boss habe mir einen Ring geschenkt, so wären Sie mit Sicherheit getäuscht. Wenn ich aber erzählt hätte: "Am 15ten Mai habe ich im Wachen einen Brief an Reck geschrieben”, so wäre der Hinweis auf meinen Wachzustand absurd. 
Wie wird das Wort "Traum" in der Erzählung des Boss-Traumes verwendet? Es gehört zwar nicht zur Sache, wo Boss mir einen Ring schenkt, aber es ist für meine Erzählung unerlässlich. Warum? Weil an der Erzählung der Boss-Ring-Sache sie nirgends erkennen können, dass es ein Traum war. Wenn ich sage: "Ronaldo hat ein herrliches Tor geschossen!", brauche ich nicht eigens zu erwähnen, dass ich vom Fussball spreche, weil Ronaldo allgemein als ein Fussballspieler bekannt ist und das Torschiessen zum Fussballspiel gehört. Mit dem Traum verhält es sich anders. Es gibt nichts, was eigens zum Traum gehört, so dass wir aus einer Traumerzählung erkennen würden, dass es ein Traum ist. Selbst die verrücktesten Sachen könnten genausogut in einer Phantasie, einer Halluzination, einem Märchen, im Fabulieren oder sogar in einer Lügengeschichte vorkommen. Und übrigens, wenn die Behauptung zuträffe, dass die Traumerfahrungen sich von denen des Wachens unterscheiden, dass es also Traumerfahrungen gibt, dann müsste ein Traum schon in der unauffäligsten Erzählung als solcher erkennbar sein, so wie das Fussballspiel in der Beschreibung jeder Phase erkennbar ist. Dann muss man aus dem Satz "Boss schenkte mir einen Ring” erkennen, dass es ein Traum war. Wenn Sie es nicht können, dann hat das Wort "Traumerfahrung" keinen Sinn und der behauptete Unterschied ist unbrauchbar.

Damit meine ich keineswegs, Traum und Wachen seien ein undifferenziertes Gemisch. Ich will nur mir Klarheit darüber schaffen, wie das Wort "Traum" ins Spiel kommt. Und nun versuche ich, dieses "Spiel” zu beschreiben: Ich erwache und - es kommt mir das Wort: Traum! Genauer gesagt, es ist kein Wort, sondern ein Name. Man könnte den Namen "Traum” mit einem Doppelpunkt vergleichen: er gibt eine Aussicht frei, wo alles von einem bestimmten Licht beschienen ist: Da ist der unbekannte Ort; Da ist Boss; Da bin ich; Da schenkt er mir einen Ring.

Ich kenne dieses Licht aus anderen Fällen, wo ich erwacht bin und der Name "Traum" laut oder lautlos mir zugesprochen hat. Jedesmal sehe ich mich da drin, diesmal mit Boss und dem Ring. Man könnte sagen, dass Boss mir den Ring im Namen des Traumes schenkt, wenn wir hier das “in... ” wortwörtlich hören: Es ist in diesem Lichte, dass die Boss-Ring-Geschichte stattfindet.

Der Traum als Traum wäre also ein Phänomen des Erwachens. Das Phänomen des Traumes wäre aber nicht im "Traummaterial”, in den "Traumbegebenheiten" zu suchen - diese sind ja nicht traumspezifisch -, sondern in jenem Licht. Dazu könnte Einiges gesagt werden, wenn wir das Erwachen nicht auf den Menschen beschränkt vorstellen, der morgens die Augen aufmacht. Das Erwachen ist nämlich nicht ohne den Aufgang der Sonne denkbar. Erwachen und aufbrechendes Licht sind eins und 
dasselbe, genauso wie, Parmenides, Vernehmen und Sein eins und dasselbe ist. Es ist gerade dieses, das aufbrechende Licht, das den Ort der Träume bescheint. Besser: Was von diesem Licht beschienen, erscheint im Namen des Traumes. Aber von welchem Licht ist jetzt die Rede? Lässt es sich noch näher beschreiben?

Was ich dazu sagen kann, habe ich mittelbar von Boss gelernt - ich weiss nicht mehr, ob ich es gelesen oder von ihm gehört habe: Eine Frau sieht eine Maus in der Küche herumlaufen. Sie schreit, springt auf dem Stuhl usw. Boss sagt nun, die Frau sehe nicht das blosse Tierchen "Maus". Denn die Maus, während sie aus dem Dunklen der Erde herauf- und hereinschleicht, bringt dieses Dunkle mit - herauf ins Freie und herein ins Haus. Das sei es, was die Frau sieht und mit Panik beantwortet. Es ist analog zum Denken des späten Heidegger, der die Unverborgenheit als die sich entbergende Verbergung fasste: Das Entborgene wird nicht der Verbergung geraubt, wie es noch in "Sein und Zeit" steht. Entborgen wird das Sich-Verbergen als solches. Erst die Maus hat es mir deutlich vor Augen geführt. Es waren solche Augenblicke, die Boss zu meinem Lehrer machten.

Im aufbrechenden Licht bricht das Dunkle der Nacht auf! Im "Es" des Ausdrucks "Es tagt" ist die Nacht angesprochen: Die Nacht tagt! Von hier aus wäre Heraklits Spruch zu hören: Tag und Nacht - einendes Eins. Es ist das Lichtlose, das im Licht als solches sich lichtet. Der erwähnte neugriechische Dichter spricht vom "engelhaften und schwarzen Licht".

Wozu Dichter? - könnte man mit Hölderlin und Heidegger und mit dem gemeinen Verstand fragen. Weil je aufmerksamer das Auge, desto dichterischer sein beschreibendes Sagen. "Aufmerksamkeit ist das natürliche Gebet der Seele”. Es ist ein Satz von Malebranche, der über Walter Benjamins Kafka-Studien von Paul Celan übernommen wurde. Die Aufmerksamkeit ist eine Sache des sagenden Auges - des äugenden Sagens -, das dem Wirklichen versprochen ist. Die Genauigkeit dagegen ist eine Sache des vorstellenden Denkens, dem es um seine eigene Sicherstellung geht. Der angehende Therapeut hat seine Aufmerksamkeit zu schärfen und das Denken abzugewöhnen.

Zurück zum Erwachen. Die Träume, könnten wir jetzt sagen, gehören zu jenem Dunklen des Schlafes, d.h. der Nacht, das, wie Bosses Maus, im aufbrechenden Licht aufgeht. Dort, in diesem Licht, bei den Toren der Sonne, haben die Träume ihren Ort. Dort ist ihre Gemeinde angesiedelt - weitab von den Wohnungen und den Gewöhnungen der nur-lebenden Menschen.

Nun kann ich zu meiner Beschreibung Folgendes hinzufügen: Die Art und Weise, in der beim Erwachen mir ein Traum in den Sinn kommt, ist anders als etwa 
eine Erinnerung, z.B. an den Reck-Brief. Der Traum ist kein Gedächtnisphänomen (Wittgenstein). Die Weise seines In-den-Sinn-Kommens ist eher die eines Aufbruchs. Man könnte es mit einem Wort Heraklits wiedergeben: AGCHIBASIẼ, "Nahegehen", besser: "Nahgang". Vermutlich ist es ein Name für das einende Eine, wenn im engelhaften und schwarzen Licht Tag und Nacht, Wachen und Schlaf, Leben und Tod nahe zueinander kommen.

So gesehen, gehören die Träume weder zur einen Seite (Schlaf) noch zur anderen (Wachen), so wie die Maus, die weder zum Dunklen der Erde noch zum Offenen des Freien gehört. Sie zeigen sich aus jener, um ein treffendes aber selten über Freud hinaus bedachtes Wort Freuds zu gebrauchen, "freischwebenden" Mitte heraus, die sich dem Aufmerksamen öffnet.

Wenn die Träume aus dieser Mitte heraus- und zur Seite des Wachens herübergezogen werden, dann werden sie in den Dienst einer "Therapie" gestellt, die eine wie auch immer zu verstehende "Gesundheit", "Selbstverwirklichung", "Offenheit” usw. sich zum Ziel gesetzt hat. Wenn die Träume zur Seite des Schlafes herübergezogen werden, dann entweder schlagen sie ins Magische um, etwa im Sinne des Prophetischen, des Symbolischen, des Archetypischen usw., oder sie gehen in die Maschinerie des Schlaflabors unter.

Das Übertreten des Masses kann aber auch hinsichtllch der erwähnten Zeitlosigkeit der Träume erörtert werden: Wenn ihr Freischwebendes auf die Seite der Vergangenheit schlägt, dann kommt es zur genetischen Deutung der Psychoanalyse freudianischer Provenienz; wenn auf die Seite der Zukunft, dann werden die Träume z.B. in Hinsicht auf unvollzogene Möglichkeiten ausgelegt, wie etwa in Bosses "Daseinsanalyse".

Man könnte wiederum einwenden: "Willst du denn das Offenbarste leugnen, dass ein Traum mit dem Leben des Träumers doch immer irgendwie zusammenhängt? Dass der Traum ihm doch etwas bedeutet?" Ich antworte: Natürlich hängt mein Traum mit meinem Leben zusammen. Hätte je mein fünfjähriger Sohn von Medard Boss träumen können? Aber das sagt nichts weiteres als: Was ich immer wahrnehme, wird irgendwie unter den Bedingungen meines Lebens wahrgenommen. Damit spreche ich keinem Solipsismus das Wort. Ich denke eher an den Vorsokratiker Xenophanes, der soll geschrieben haben: Wenn aber Rinder und Pferde und Löwen Hände hätten und wie Menschen mit den Händen zeichneten und werkten, dann würden die Pferde pferdehafte und die Rinder rinderhafte Bildnisse der Götter zeichnen und Körper schaffen von solcher Gestalt, wie sie selbst haben. 
Insofern das Geträumte nach dem “Augenmass” erscheinen muss, insofern also eine Zusammenhangslosigkeit zwischen Träumen und Wachen undenkbar ist, rennt der Zusammenhänge Suchende offene Türen ein.

Und jetzt ein Traum von mir aus meinen ersten zürcher Jahren: Ich bin bei der Facharztprüfung. Ein mir unbekannter Oberarzt ist mein Prüfer. Er fragt mich, ob ich altgriechisch kann. Ich wundere mich, was denn das Altgriechische mit der Psychiatrie zu tun hat. Es ist Tatsache, dass ich mich in den Jahren danach immer intensiver mit altgriechischen Texten beschäftigte. Kann ich hier von einem Zusammenhang zwischen dem Traum und meinem Wachleben sprechen? War es z.B. ein prophetischer Traum? Oder ein archetypischer? Ist die Altgriechischprüfung die verschobene und verdichtete Gestalt von Situationen aus meiner frühen Kindheit? Hat mich der Traum auf noch unvollzogene Möglichkeiten aufmerksam gemacht?

All die Fragen... Ich überlege sie mir. Ich merke, dass ich keiner von ihnen nachgehen will. Es ist zunächst eine Ahnung, die mich unwillig macht. Sie würde zugundegehen, wenn ich mich auf eine der vorgeschlagenen Deutungen einliesse und einen Zusammenhang meines Traumes mit meinem Wachleben herzustellen versuchte. Das will ich ihr nicht antun. Ich horche. Es heisst, was ich suche sei schon da. Aus ihrer Ferne kommt der Hauch eines Aufatmens, besser, der leise Wind einer, und hier gebrauche ich mit aller Vorsicht ein Wort Paul Celans, Atemwende.

Nun glaube ich, es klarer zu sehen: Dieser Traum ist von meiner Beschäftigung mit dem Altgriechischen im Wachen nicht mehr wegzudenken. Mit anderen Worten: Das Altgriechische ist nicht mehr bloss Sache meines Wachlebens. Seine Reichweite übetrifft die des Wachen unendlich: Es ist nunmehr vom Traumhaften gezeichnet, so wie der Jude der Nazi-Zeit von seinem Stern - seinem Schicksal - gezeichnet ist. Aber so ist es auch mit Boss und mit all den Menschen und Dingen, denen ich je im Traum begegnet bin. Sie alle sind nun vom Traumstern gezeichnet. $\mathrm{Zu}$ ihnen gesellen sich noch der Ort und der Ring und all die Menschen und Dinge, die mir im Wachen unbekannt sind.

Diese Wesen versammeln bei sich Wachen und Traum. Die Spannweite dieser Versammlung reicht vom Dr.-Karl-Lueger-Ring bis zu den Toren der Sonne. Prospero sagt einmal in Shakespears Gewitter:

Wir sind aus dem Stoff, aus welchem die Träume gemacht sind und unser kleines Leben wird von einem Schlaf umgeben.

"Von einem Schlaf umgeben" heisst: von Verweisungen und Bezügen und Verbindungen unantastbar, ohne vorher und danach, ruhend bei sich selbst: 
unheimlich. Und was wird dann aus dem Zusammenhang, der ja Wachen und Traum zueinander versammeln soll? Er ist von der Art der Bäume eines Waldes. Heidegger (Heidegger, 1983, 85) deutet ihn einmal durch Verse Hölderlins an:

Und unbekannt einander bleiben sich sich, Solang sie stehen, die nachbarlichen Stämme.

Langsam wird es mir klarer, worauf sich mein Entsetzen vor der Aussicht, einen Vortrag unter dem Titel "Träume" zu halten, bezog. Es war die Aporie, wie von den Träumen sprechen zu können, ohne über die Träume sprechen zu müssen - und dies unter anderem auch als Therapeut, d.h. als Einer, dessen Rede zwar jetzt Sie anspricht, aber eigentlich dem vor meinem Sessel und auf dem Couch Liegenden zugewandt ist. Damit meine ich nicht, dass ich je das Vorangegangene ins therapeutische Gespräch gebracht hätte. Diese Ausführungen sind eher einer Notenschrift vergleichbar, die ja erst in der musikalischen Praxis zur Wirklichkeit eines Werks wird. Wie das nun in der Therapie vor sich geht, werde ich versuchen, zunächst anhand der Traumerzählung einer Frau zu beschreiben:

Sie ist in der Analysestunde; Arbeitskollegen sind mitanwesend; einer bringt ihr ein Glas Wasser; er stellt es aufs Kissen; es kippt um; ich wische das Wasser vom Boden; sie steht auf und wartet draussen; ist böse mit mir wegen all dem Chaos; denkt, sie wolle die Stunde nicht zahlen... Es kommt nun zum folgenden Dialog:

Sie: Was sagen Sie zum Traum?

Ich: Was stellen Sie sich vor? Haben Sie schon irgendeine Ahnung? Hab' ich irgendwie schon etwas dazu gesagt?

Sie: Es sei nicht positiv, ich sei misstrauisch ...

Ich: Sie meinen, dass das Negative, das Misstrauen zwischen uns nicht sein darf?

[Es wird noch eine Weile darüber hin und her gesprochen. Dann:]

Sie: Und was ist mit dem Traum? Sie haben es mir nicht gesagt...

Ich: Sie sehen ja, wie Vieles vorbereitet sein muss damit wir zum Traum kommen... Sie: Und jetzt, wo wir es wissen...?

Ich: Das genügt nicht. Zuerst müssten Sie von all dem frei werden. Der Traum kommt nachher... Die Frage, die wirklich nach dem Traum fragt, ist noch nicht gestellt!

Was kommt hier dazwischen? Die Frau hat ihren Traum schon gedeutet, nämlich als Zeichen für ein Misstrauen mir gegenüber, das sie überdies als "negativ" wertet. Insofern ist ihre Frage an mich: "Was sagen Sie zum Traum?" unzutreffend. Richtig gestellt, hätte sie etwa die Form: "Sehen Sie den Traum ebenfalls negativ?" Oder sogar: "Sie Sehen doch, etwas klappt zwischen uns nicht!"

Über das Misstrauen und das Negative kann man mit der Frau sprechen, was ich ja auch getan habe. Man kann ferner auf ihre Neigung hinweisen, gleich das 
"Negative" herauszuhören. Dies und anderes noch könnte mit ihr erörtert werden und es wäre auch therapeutisch sinnvoll. Bloss hat es mit ihrem Traum nichts zu tun. Denn ihre Frage an mich bezieht sich auf ihre und meine angebliche Deutung, und diese Deutung ist in Tendenzen und Neigungen ihres Wachlebens vorgezeichnet.

Das gilt auch für die mehr ausgeklügelten "professionellen" Traumdeutungen und -auslegungen. Die Fragen, mit denen sie sich einem Traum zuwenden, z.B. "Welcher unbewusste Wunsch wird im Traum erfüllt?", oder: "Welche noch unvollzogene Möglichkeiten melden sich da?” usw., haben ihren Vor-urteil zur Sache der Träume schon gefällt: Der Traum sei Wunscherfüllung; der Traum sei die sinnlich gegenwärtig wahrnehmbare Version unvollzogener Möglichkeiten usw. Insofern sind sie keine echte Fragen: Sie reichen nicht bis zum Traum heran. Sie sind keine Fragen, die es einem Traum erlauben, im Offenen zu atmen. Sie sprechen von Wachen her aufs Wachen zu, den Pferden und Löwen des Xenophanes vergleichbar. Sie reichen nicht bis zum "Ungleichen an Gestalt und Undenkbaren", das in einem anderen Fragment genannt wird, und das hier als das Unheimliche der Träume angesprochen wurde. Die "Frömmigkeit des Denkens" (Heidegger) fehlt ihnen. Dies ohne grosse Worte und missionarischen Eifer im therapeutischen Gespräch zu zeigen, würde zur erwähnten Vorbereitung gehören.

Die verschiedenen Thesen zum Traum stehen Antwort zu einer Leitfrage, die lautet: "Was ist der Traum?" oder, ins Psychologische gewendet: "Was bedeutet der Traum?". Hier ist stillschweigend angenommen worden, dass der Traum etwas ist; etwas bedeutet. Die uralte Gewohnheit, in diesem Stil zu fragen und zu sagen, hat die fatale Folge, dass man sich vom Traum weg und auf dieses Etwas hin orientiert wird. Die Träume werden aus ihrem Ort hinausgejagt - ihrem Ort, ich erinnere halb im ernst halb im Scherz, bei den Toren der Sonne und der Asphodeloswiese; sie werden auf den Markt der psychologischen und neurobiologischen Verrechnungen geworfen.

Eine halbe Stunde, bevor ich diese Überlegungen erstmals notierte, bekam ich eine Traumerzählung von einer Psychologin zu hören. Und dann:

Sie: Haben Sie etwas zum Traum zu sagen?

Ich: Was steht hier überhaupt in Frage? In Hinblick worauf fragen Sie mich?

Sie: Ich frage nach einer Erklärung des Traumes.

Ich: Und was erwarten Sie von einer Erklärung? Was wäre nach der Erklärung anders?

Sie: Ein besseres Verständnis von mir selbst, von diesen Dingen.

Ich: Haben Sie so etwas schon erlebt? Dass eine Erklärung Ihnen in diesem Sinne geholfen hat?

Sie: Einmal hat mir ein Traum geholfen, eine wichtige berufliche Entscheidung zu treffen. Ein anderes Mal habe ich anhand eines Traumes einen Fehler von mir in einer Arbeit erkennen können. 
Es gibt wiederum Fälle, wo ich zu einer Frage im Stil von "Was bedeutet der Traum?" schweige, oder antworte: "Ich weiss nicht".

Es geht mir, und das habe ich von Parmenides und den Alten, von Heidegger und Wittgenstein gelernt, um die Schärfung des Auges für die Unterscheidung zwischen dem, was sich fragen und sagen lässt und dem, worüber das Fragen und Sagen sinnlos ist.

Diese Haltung, die sich ja nicht auf die Träume beschränkt, bringt oft Ärger und wiederholtes Anrennen gegen meine Weigerung, dort mitzumachen, wo Grenzen überschritten werden. Aber nur so lernt Einer: nicht durch Deutungen und Erklärungen, sondern durch die Stösse gegen die Wand seiner Unmöglichkeiten - seiner Sinnlosigkeiten -, an welche diese vom Therapeuten gemalt werden. Der Therapeut muss oft Beispiel für diese Wand stehen.

Es ist kein Dozieren. Und kein Pathologisieren. Es geht mir um unsere Begegnung, besser, um die Flurreinigung, wo wir uns zuweilen begegnen, d.h. sprechen, d.h. hören können voneinander (Hölderlin). Es glückt, wenn wir zu der in Frage stehenden Sache wirklich kommen: wenn wir uns im Ton ihres Masses finden - der Akzent liegt auf den "Ton”, nicht auf "uns”.

Die therapeutische Begegnung, wenn man hier noch überhaupt von "Therapie" sprechen kann, hätte dann eben den Charakter der Aus-einander-setzung. Im Spiel stehen die Masse, d.h. die Unterschiede, überall dort, wo gegen sie vergangen wird. Sie wird aber vom Therapeuten nicht feindselig, sondern in einer Stimmung der Akzeptanz ausgetragen. Er weiss ja, dass unsere Wege nur sich vergehenden Schrittes gangbar sind. Sein Gesprächspartner wird angehalten, vor allem dies zu beherzigen.

Wo diese Begegnung einigermassen glückt, wo, wie Hölderlin in einem späten Gedicht schreibt, "höher zeigen die Unterschiede sich", wird das Heimliche heimlicher und das Unheimliche unheimlicher und das Leben, wiederum Hölderlin, ein "wohnend Leben".

Ob ich die Frage nach den Träumen zu einem Abschluss gebracht habe? Mitnichten! Ich breche nur ab, wie ein Wanderer, der sich erschöpft niederlegt und die Konturen von Start und Weg und Ziel in der Ermattung verschwommen werden und in den Schlaf mitentgleiten. Und Gott weiss, wo er sich wiederfindet, wenn er aufwacht. Und was er hier und heute sagte, wird ihm morgens scheinen, als wäre es ein Traum. 
Das Fernsehspiel wurde im Auftrag des Süddeutscher Rundfunks geschrieben. Es wurde erstmals im Mai 1983 gesendet. Eigentlich handelt es sich um eine Regieanweisung, die erstmals auf English veröffentlicht wurde:

Elements.

Evening light.

Dreamer $(\mathrm{A})$.

His dreamt self (B).

Dreamt hands R (right) and L (left).

Last 7 bars of Schubert's Lied, Nacht und Träume.

1. Fade up on a dark empty room lit only by evening light from a window set high in back wall.

Left foreground, faintly lit, a man seated at a table. Right profile, head bowed, grey hair, hands resting on table.

Clearly visible only head and hands and section of table on which they rest.

2. Softly hummed, male voice, last 7 bars of Schubert's Lied, Nacht und Träume.

3. Fade out evening light.

4. Softly sung, with words, last 3 bars of Lied beginning "Holde Träume ..."

5. Fade down A as he bows his head further to rest on hands. Thus minimally lit he remains just visible throughout dream as first viewed.

6. A dreams. Fade up on B on an invisible podium about 4 feet above floor level, middle ground, well right of centre. He is seated at a table in the same posture as A dreaming, bowed head resting on hands, but left profile, faintly lit by kinder light than A's.

7. From dark beyond and above B's head L appears and rests gently on it.

8. $B$ raises his head, $L$ withdraws and disappears.

9. From same dark R appears with a cup, conveys it gently to B’s lips, B drinks, R disappears.

10 . $\mathrm{R}$ reappears with a cloth, wipes gently B's brow, disappears with cloth.

11. B raises his head further to gaze up at invisible face.

12. $B$ raises his right hand, still gazing up, and holds it raised palm upward.

13. $\mathrm{R}$ reappears and rests gently on $\mathrm{B}$ 's right hand, $\mathrm{B}$ still gazing up.

14. B transfers gaze to joined hands.

15. $B$ raises his left hand and rests it on joined hands.

16. Together hands sink to table and on them B's head.

17. L reappears and rests gently on B's head.

18. Fade out dream.

19. Fade up A and evening light.

20. A raises head to its opening position.

21. Lied as before (2).

22. Fade out evening light.

23. Close of Lied as before (4).

24. Fade down A as before (5).

25. A dreams. Fade up on B as before (6).

26. Move in slowly to close-up of B, losing A. 
27. Dream as before (7-16) in close-up and slower motion.

28. Withdraw slowly to opening viewpoint, recovering A.

29. Fade out dream.

30. Fade out A.

Schuberts Lied entstand 1825. Den Titel übernahm Beckett für sein Fernsehstück. Die Verse schrieb Matthäus von Collin:

Heil'ge Nacht, du sinkest nieder;

Nieder wallen auch die Träume

Wie dein Mondlicht durch die Räume,

Durch der Menschen stille Brust.

Die belauschen sie mit Lust;

Rufen, wenn der Tag erwacht:

Kehre wieder, heil'ge Nacht!

Holde Träume, kehret wieder! ${ }^{5}$

Beckett hat im Titel seines Werkes nicht zufällig denjenigen des Lieds übernommen. Seine "Nacht und Träume" ist eine filmische, eine figürliche Darstellung des gleichnamigen Lieds, das in den letzten Vers "holde Träume kehret wieder" gipfelt. Sie folgt diesem Geheiss und stellt die Wiederkehr der "holden Träume" dar.

\section{Erste Szene:}

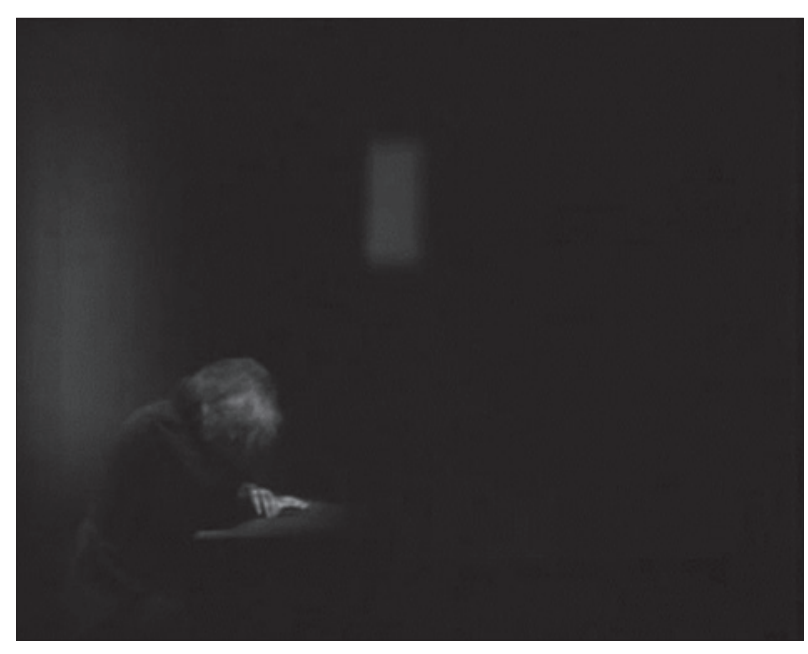

Die anwesenden Dinge, Fenster, Mann, Tisch sind in einer eigenartigen Luft eingetaucht. Diese Luft lässt sie in einer entsprechenden Art und Weise erscheinen:

Clearly visible only head and hands and section of table on which they rest.

Es gibt keine klaren Konturen, will heissen, die Dinge sind nicht in ihrer jeweiligen Identität festgenagelt. Es ist eine seltsame Offenheit, eine Verfügbarkeit, die das Hinübergleiten in andere Seinsweisen ermöglicht, in die nämlich des Schlafens und des Träumens.

\footnotetext{
5 Hier in der Interpretation von Kwangchul Youn.
} 
Der Mann sitzt. Es ist also ein Schlaf, der nicht nach dem ins Bett Gehen erfolgt. Das Einschlafen im Sitzen ist in einem emphatischeren Sinne Schlaf, da er nicht im gewöhnlichen Nacheinander (Ins-Bett-Gehen, Einschlafen) erfolgt. Er kommt unerwartet.

Softly hummed, male voice, last 7 bars of Schubert's Lied, Nacht und Träume.
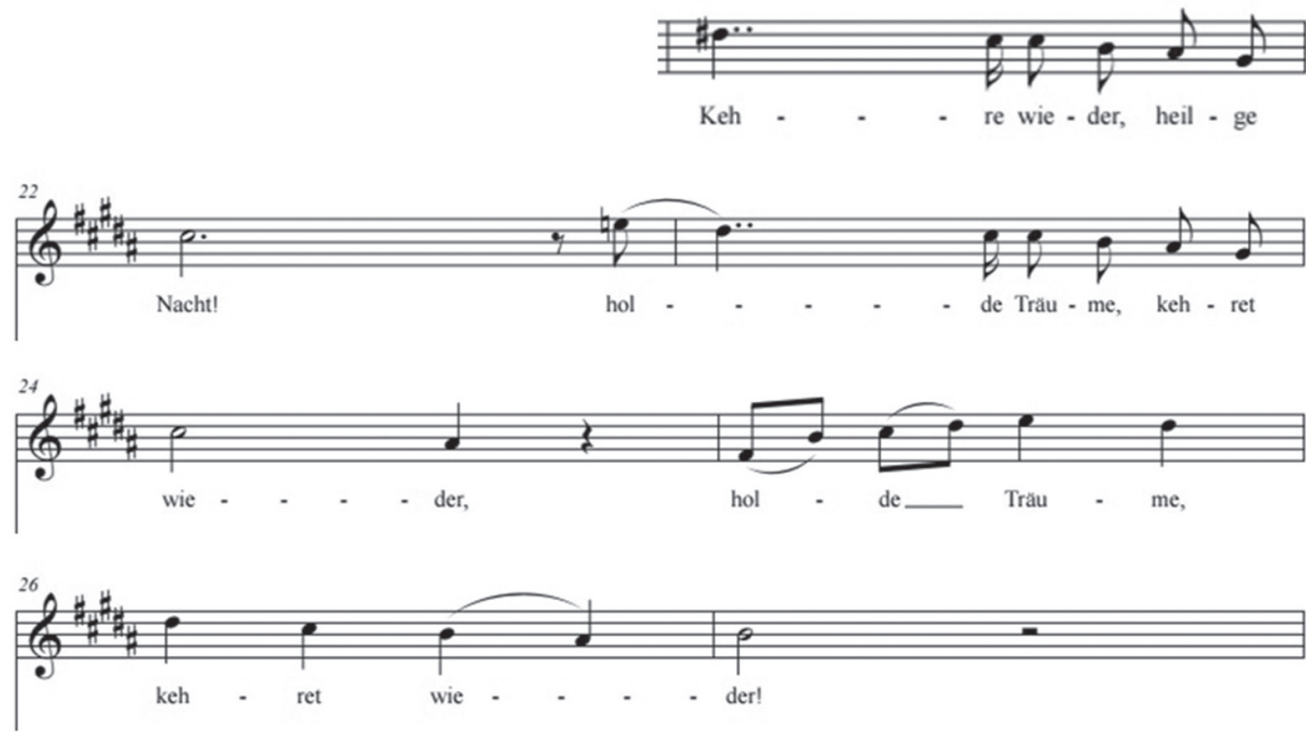

Die Melodie, ein sanftes Summen, das nach einer kurzen Pause in den Gesang übergeht:

Holde Träume, kehret wieder,

Holde Träume, kehret wieder!

Es ist ein "male voice", eine männliche Stimme a capella. Sie wird keinem zugerechnet, keiner menschlichen Figur, sie wird nicht einmal vom Klavier begleitet, wie in Schuberts Lied. Es scheint, wie wenn die Stimme zu Wort brächte, was in der Luft liegt. Es ist, wie wenn diese Luft selbst wäre, die spricht, singt. Die schwangere Luft gebiert die Stimme, welche den Träumen zuruft, zusingt, heisst sie wiederkehren. Sie lässt die Träume kommen.

Und sie kommen. 
Was kommt, sind nicht bloss Träume. Es kommt das "dreamt self" des Träumers, sein träumendes Selbst. Der Träumende ist ein Anderer als der Träumer, wobei das Arrangement (Haltung, Tisch) das selbe bleibt. Gerade diese Wiederholung im Traum macht den Unterschied besonders augenfällig. Wiederum sind der Träumende, die Traumdinge,

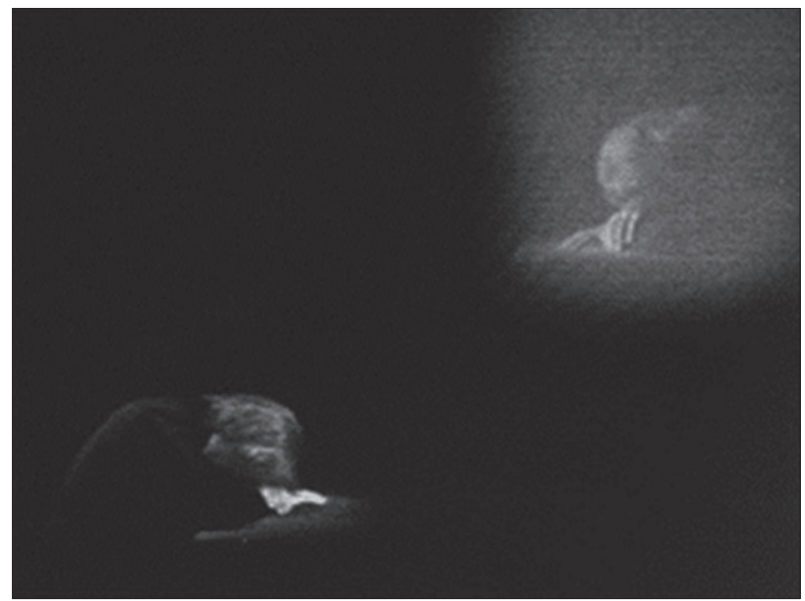
Tisch, Hände, Becher, Tuch nicht in einer festen Identität niedergeschlagen. Hier alles zeigt sich und zugleich verbirgt sich. Es ist diejenige präsenz, die Heraklit $\Sigma$ HMA, Zeichen genannt hat.

Ein Zeichen sind wir... (Hölderlin, Mnemosyne)

Eine unendliche Zärtlichkeit durchstimmt die Traumgeschehnisse. Am Ende ruht die wohlwollende Hand auf dem Kopf des Träumenden.

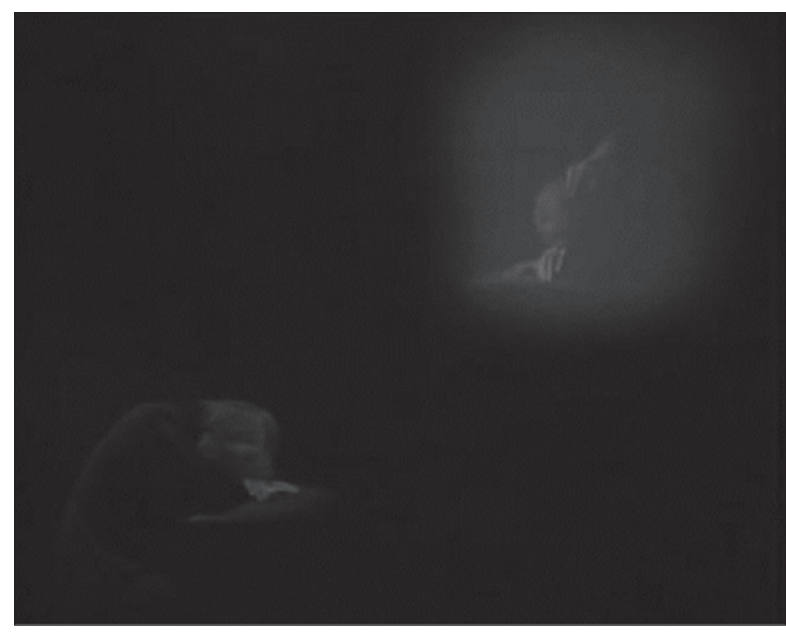

Dream as before in close-up and slower motion.

Nun in dieser seconda Volta ist der Schlafende verschwunden: 


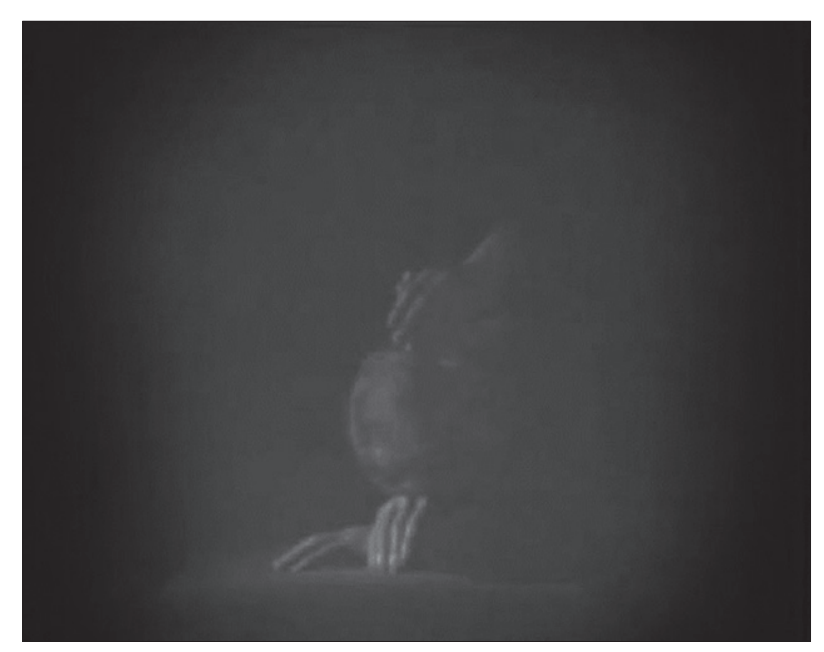

Die Traumsequenz wiederholt sich langsamer. Das Zeichenhafte von Menschen und Dingen, die Ausdrucks- und Gefühllosigkeit, die Stille lassen das "Holde" selbst in "Close-Up" erscheinen. Wie gesagt, Becketts Werk liefert keine Interpretation der Träume. Es transportiert, freilich auf seine Art, Schuberts Lied ins Fernsehen.

Gegen Ende des Spiels tauchen Träumer und Träumender, ihre Orte, ihre Zeiten ins Finsternis. 
Der "Schmetterlingstraum" des chinesischen Weisen Dschuang Dsi. Er hat mich besonders beschäftigt, vor allem in der 1989 erschienenen Studie Der Traum und in dem Vortrag aus dem Jahre 2007 Nachklänge des Schmetterlinstraums.

Einst träumte Dschuang Dschou, dass er ein Schmetterling sei, ein flatternder Schmetterling, der sich wohl und glücklich fühlte und nichts wusste von Dschuang Dschou. Plötzlich wachte er auf: da war er wieder wirklich und wahrhaftig Dschuang Dschou. Nun weiß ich nicht, ob Dschuang Dschou geträumt hat, dass er ein Schmetterling sei, oder ob der Schmetterling geträumt hat, dass er Dschuang Dschou sei [...]. (Dschuang Dsi, 1969, 52)

Diesen Frühling sind wieder Schmetterlinge im Garten erschienen. Der sich wälzende Flügelschlag, seine Zerbrechlichkeit, seine unendlichen und unvorhersehbaren krumme Linien, die plötzliche Ruhe, sobald sie kurz auf eine Blume niedersetzen, und wieder von vorne an gehts...

Anfang des 19ten Jahrhunderts stellte der japanische Maler Hokusai einen Album mit "Studien nach der Natur" zusammen. In einem von diesen Bildern werden Päonien und ein Schmetterling abgebildet.

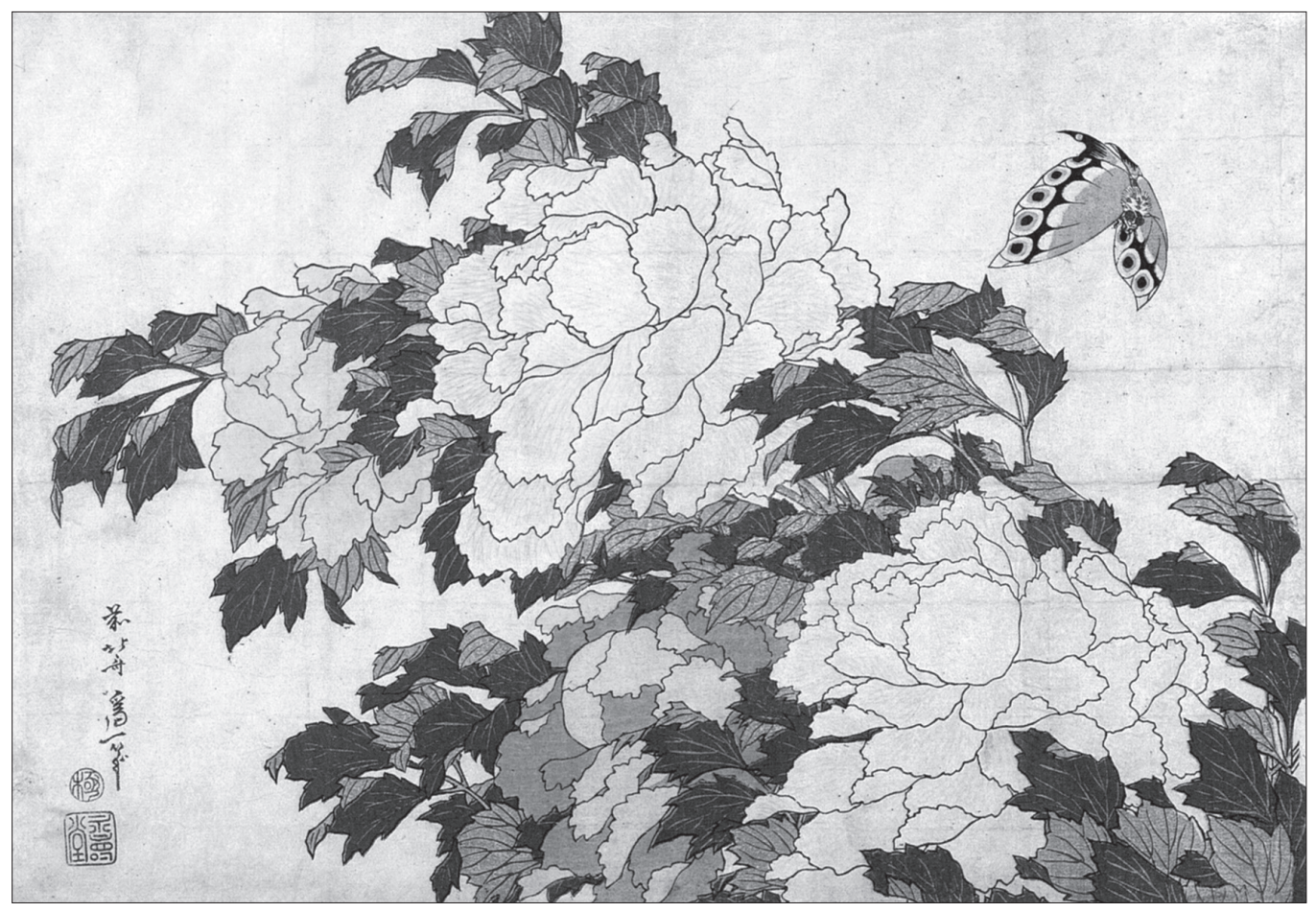


Ein Wind weht von rechts nach links. Blätter und Schmetterling neigen in die Richtung des Wehens, gleichmässig und total synchronisiert, wie Tänzer. Ihre archaische Vertrautheit zueinander.

Der Entomologe E. O. Wilson nennt die Schmetterlinge Flowers of the Air. Windblumen.

Le papillon est une fleur qui vole, La fleur un papillon fixe $e^{6}$

Von Hokusai ist auch folgendes Bild überliefert:

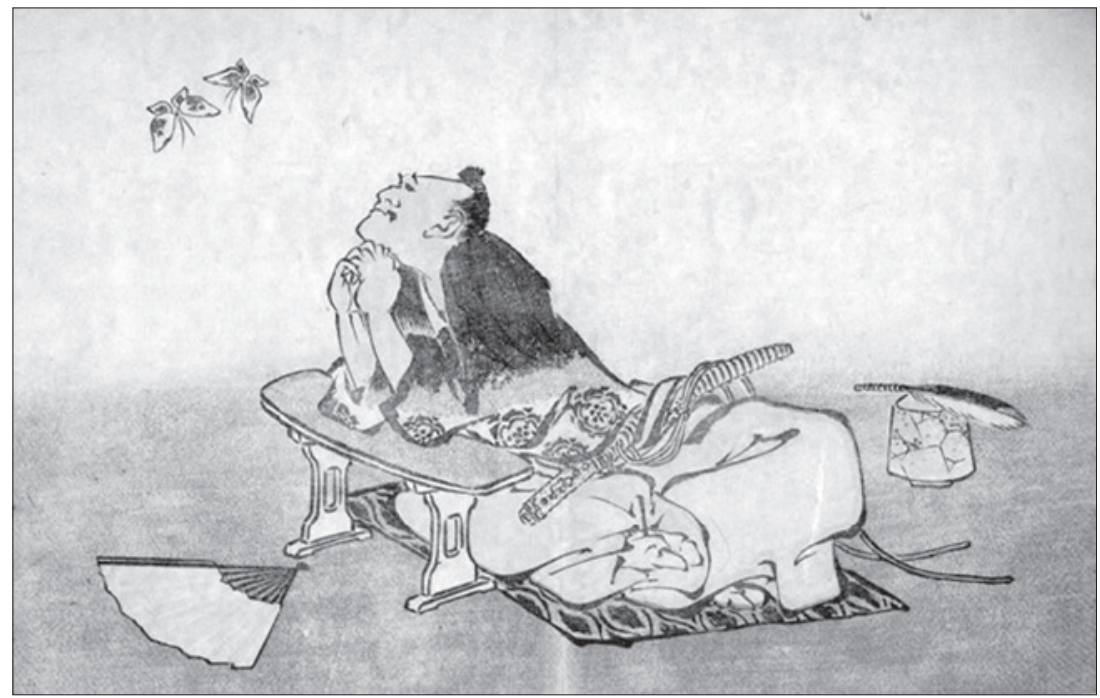

Es trägt den Titel "Der chinesiche Philosoph Sōshi betrachtet Schmetterlinge". Wie betrachtet der Philosoph?

Nicht wie ein einstiger Mexikaner, Indianer, Ostasiate, Bewohner von Mitteleuropa und Griechenland, der an ihnen Freunde und Feinde sieht: Seelen und Göttlichkeiten, gute und schlechte Omen, Geburts-, Todes- und Ewigkeitssymbole:
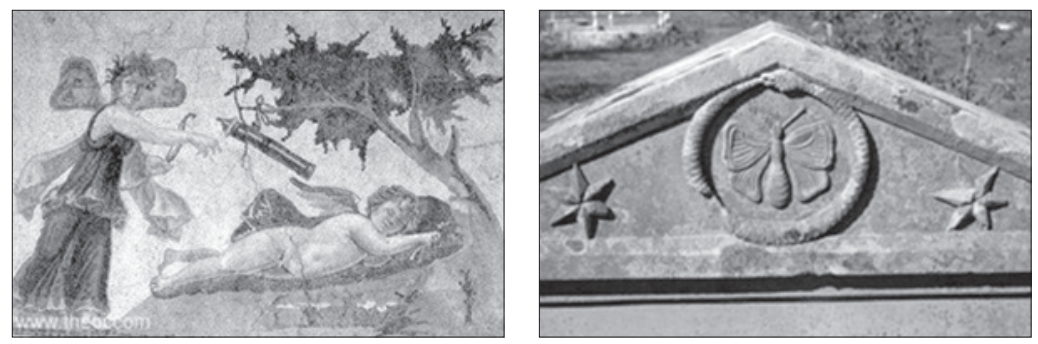

6 Ponce Denis Écouchard Lebrun,französischer Lyriker des 18. Jahrhunderts. 
Nicht wie ein Biologe mit seinem Notizenheft zur Hand, oder, nachdem er Schmetterlinge im Video aufgenommen hat, vor seinem Monitor sitzend in slow motion den Kodex ihrer Kommunikation erforscht:
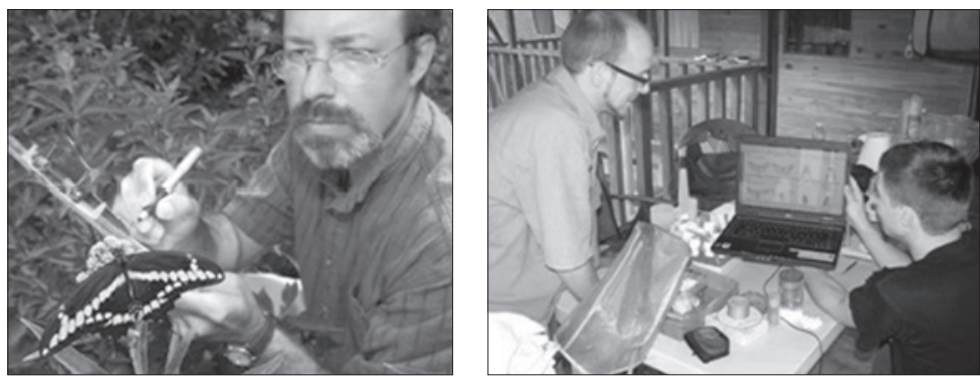

Nicht wie ein Sammler, der auf sie losgeht, sein Netz schwingt und schon sieht er sie in seinem Kasten gesteckt:
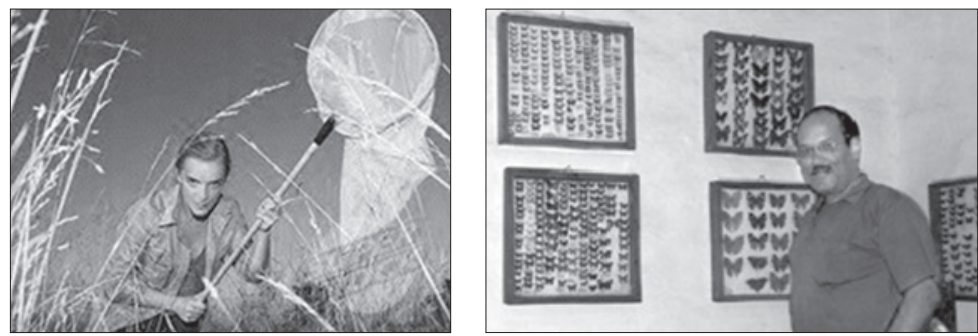

Nicht wie der Sentimentale, der vor ihrer Schönheit zuckt, vibriert und ruft "Wunderbar!":

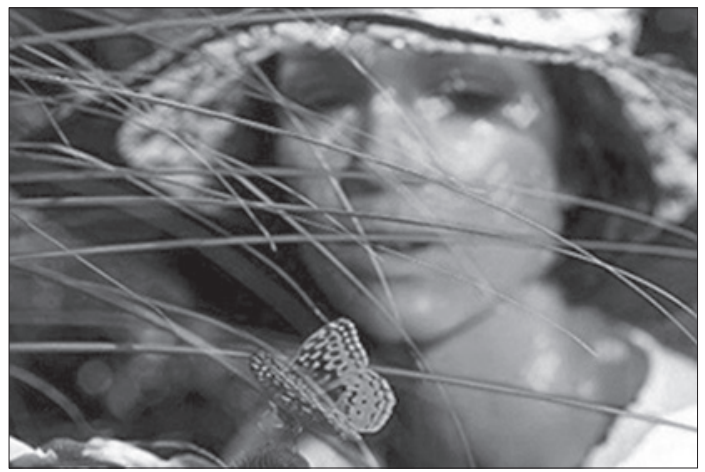

Wir sehen uns das Bild nochmals an: 


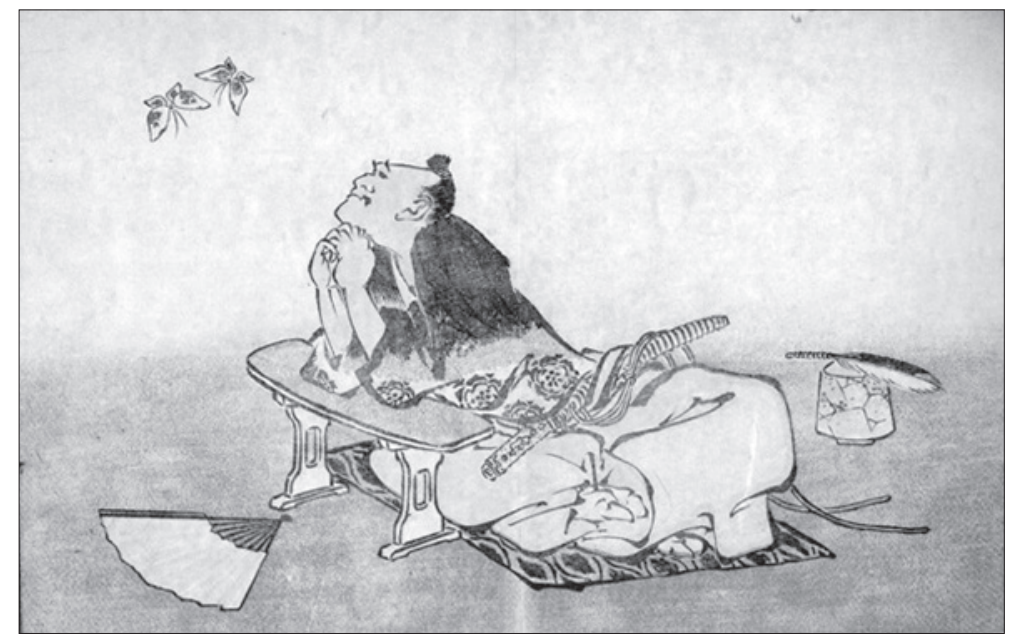

Der Philosoph befindet sich offenbar in seiner Wohnung. Er hat nicht nach den Schmetterlingen gesucht, er erwartet von ihnen nichts. Die Schmetterlinge sind zufällig in sein Zimmer eingeflogen.

Der Philosoph lässt die Schreibfeder nieder, wie auch seinen Fächer, mit dem er sich abkühlte. Er lässt jede Beschäftigung beiseite. Sein Körper. Er ist ganz nach den Schmetterlingen gerichtet:

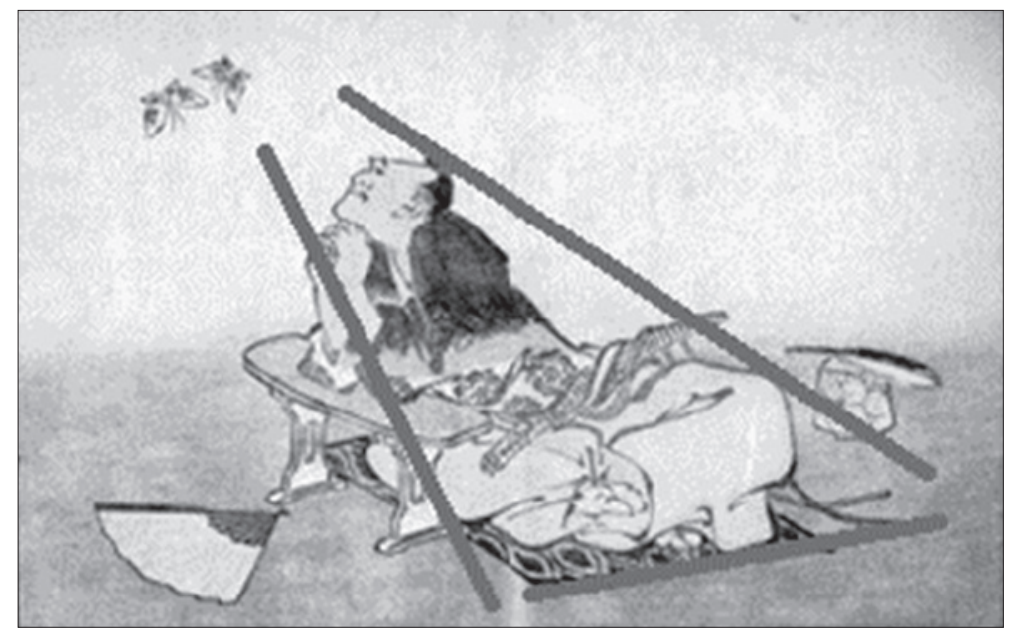


Seine Miene:

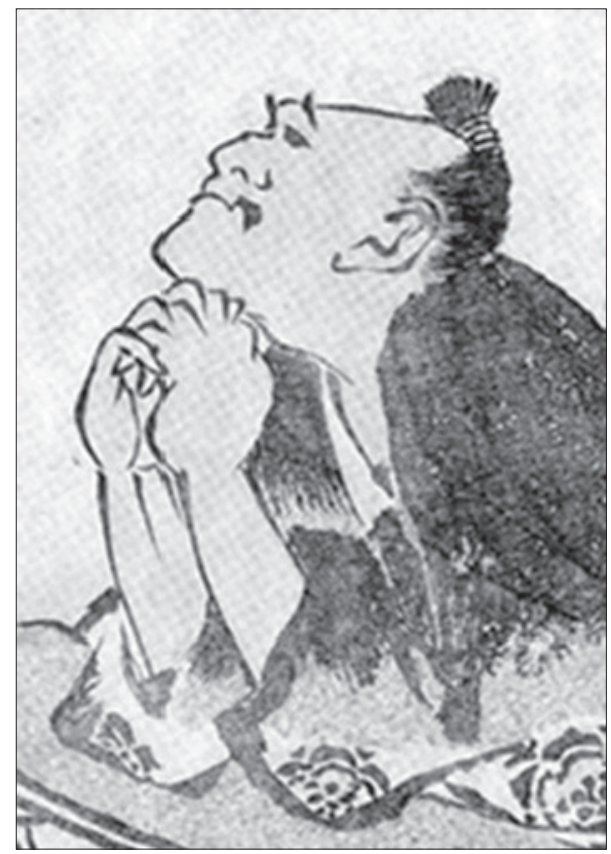

Keine Begierde, keine Intentionalität überhaupt. Mitsamt Schreibfeder und Fächer hat er alles abgesagt, was Einen üblicherweise als menschliches Wesen bestimmt.

Seine Hände. Auf dem Tisschen sich stützend, ruhig bei- und ineinander, ohne jedoch sich aneinader zu klammern. Es ist eher, wie wenn sie das Schmetterlingspaar nachahmten.
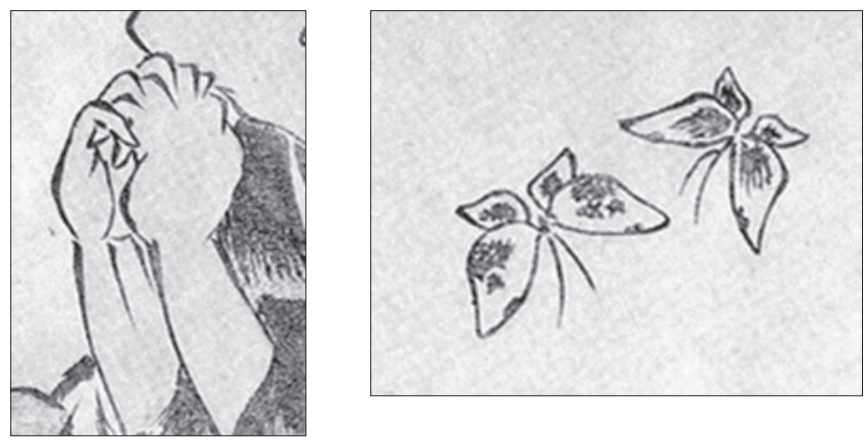
Wer ist nun dieser Philosoph? In der "Philosophie des Zen-Buddismus" erwähnt ByungChul Han eine Geschichte:

Einst ging Meister Hui-tang mit dem Laien Huang-schan-gu in die Berge. Wohlgeruch strömte ihnen auf einmal entgegen. Hui-tang frug: "Vernimmst du den Duft der Reseden?" Als Huang-schan dies bejahte, sagte Hui-tang zu ihm: "Ich habe dir nichts zu verbergen". (Han, 2002, 118)

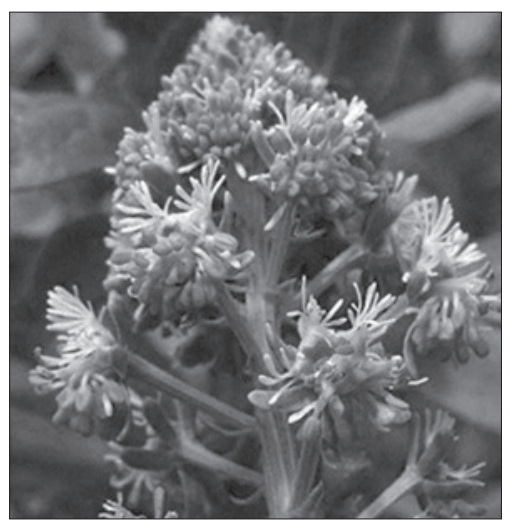

Was heißt hier "Ich habe dir nichts zu verbergen"? Han schreibt: "Der Duft der Reseden ent-innerlicht Hui-tang”. Innerlichkeit ist ein Name für den heimatlichen Ort, den das Ich, das Subjekt, die Seele, der Geist, das Denken und das Gefühl, das Bewusstsein und das Unbewusste, die Identität und das Man und das Selbst stiften. Diese Worte sind eben keine Begriffe; sie sind Orte, Häuser, die wir bewohnen. Der Duft der Reseden lässt bei Hui-tang nichts von all dem bestehen. Hui-tang geht in den Duft der Reseden auf. Er hat kein Inneres und gerade deswegen hat er nichts zu verbergen. Hui-tang ist "draußen bei den Dingen" in einem radikalsten Sinne. Er ist kein "In-der-Welt-sein" sondern, wie Han anderswo schreibt, einfach "Welt-sein".

Diese Heimeligkeit, diese Freundlichkeit zwischen dem Philosophen, dem Zhuangzi und dem Schmetterling hat nichts mit einer Ähnlichkeit untereinander zu tun. Zwei alte Bilder bezeugen es. Der Unterschied zwischen Zhuangzi und dem Schmetterling, was Statur und Grösse betrifft, wird eigens betont:

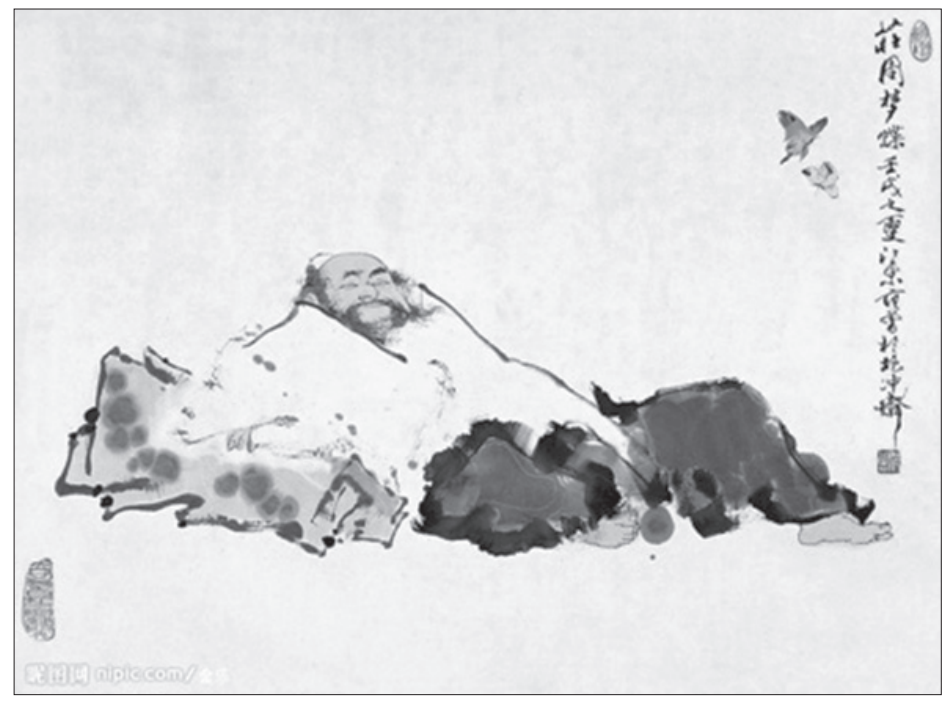




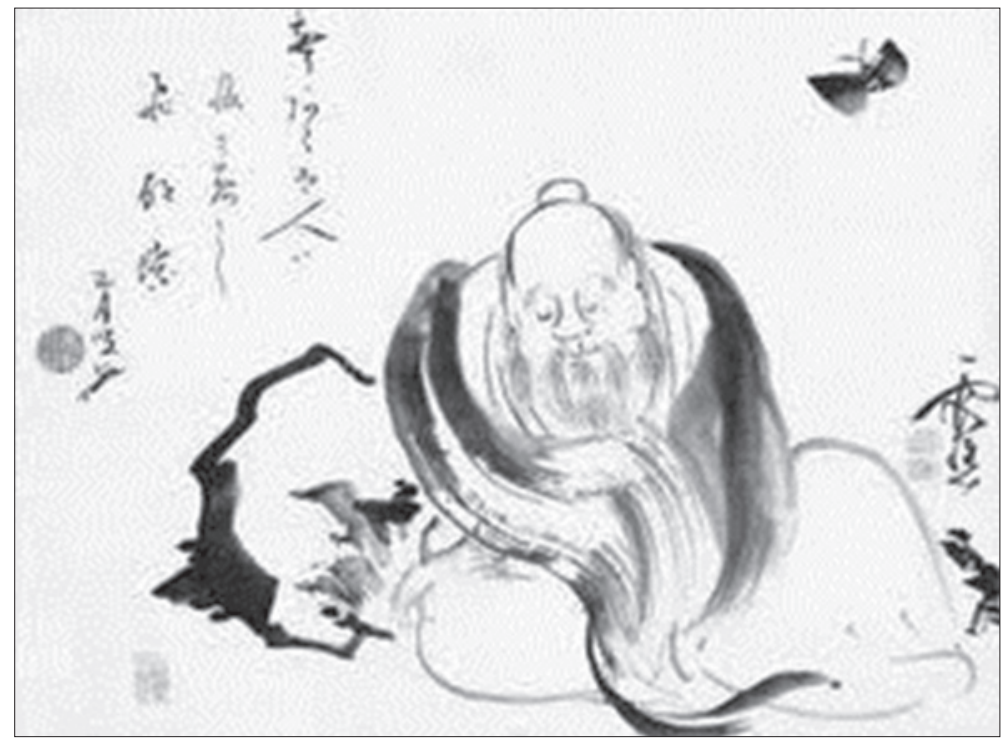

Aber gerade das macht ihre "unscheinbare Harmonie" (Heraklit) noch emphatischer:

Nun weiß ich nicht, ob Dschuang Dschou geträumt hat, dass er ein Schmetterling sei, oder ob der Schmetterling geträumt hat, dass er Dschuang Dschou sei [...]. (Dschuang, 1969)

Und nun: Der "Schmetterlingstraum" braucht nicht einfach so gehört zu werden, als wäre das "Schmetterlings...”. Genitivus Objektivus, wie wenn nämlich der Schmetterling das Objekt, das Thema eines Traumes wäre. Auch nicht als Genitivus Subjektivus: wie wenn der Schmetterling träumte. Das Entweder-Oder der Frage lässt alles in der Schwebe. Und so soll es bleiben, entgegen unserer Sucht nach Antworten.

Warum spricht Zhuangzi vom Schmetterlingstraum und nicht etwa von einem Schlangentraum, oder einem Elephantentraum? Vielleicht weil in der Gesellschaft von Traum und Schmetterling selbst eine andere "unscheinbare Harmonie" waltet. Der Titel "Schmetterlingstraum” könnte fast auf eine Tautologie hinweisen: Der Traum ist wie ein Schmetterling. Der Schmetterling ist wie ein Traum.

\section{REFERENCES}

Angelus Silesius, (1949). Cherubinischer Wandersmann. In H.L. Held (Ed.), Sämtliche poetische Werke. München: Hilfsstelle.

Aristotelis, (1832). Opera Omnia. Volumes 6-7. Leipzig: Tauchnitz. 
Beckett, S. (1986). All that Fall. The Complete Dramatic Works. London: Faber and Faber.

Boss, M. (1976). Indienfahrt eines Psychiaters. Bern: Huber.

Byung-Chul, H. (2002). Philosophie des Zen-Buddhismus. Stuttgart: Reclam.

Canetti, E. (1973). Die Provinz des Menschen. Aufzeichnungen 1942-1972. München: Hauser.

Dschuang, D. (1969). Das wahre Buch vom südlichen Blütenland. Düsseldorf: Eugen Friedrichs.

Freud, S. (1998a). Die Traumdeutung (GW II/III). Frankfurt a. Main: Fischer.

Freud, S. (1998b). Vorlesungen zur Einführung in die Psychoanalyse (GW XI). Frankfurt a. Main: Fischer.

Freud, S. (1998c). Neue Folge der Vorlesungen zur Einführung in die Psychoanalyse (GW XV). Frankfurt a. Main: Fischer.

Freud, S. (1982). Schriften zur Behandlungstechnik. Frankfurt a. Main: Fischer.

Georgiades, T. (1985). Nennen und Erklingen: Die Zeit als Logos. Göttingen: Vandenhoeck und Ruprecht.

Heidegger, M. (1976). Wegmarken (GA 9). Frankfurt a. Main: Vittorio Klostermann.

Heidegger, M. (1983). Aus der Erfahrung des Denkens (GA 13). Frankfurt a. Main: Vittorio Klostermann.

Heidegger, M. (1986). Seminare (GA 15). Frankfurt a. Main: Vittorio Klostermann.

Seferis, G. (1974). Dokimes. Athena: Ikaros.

Wittgenstein, L. (1994). Vermischte Bemerkungen. Frankfurt a. Main: Suhrkamp. 